\title{
Gerardo Boto*
}

\section{El primer proyecto gótico de Santa Maria de Castelló d'Empúries}

\author{
The First Gothic Project of Santa Maria de Castelló d'Empúries
}

\begin{abstract}
Resumen: Este estudio presenta un meticuloso análisis de la iglesia de Santa Maria de Castelló d'Empúries, sin duda uno de los edificios más originales y portentosos del primer gótico en Cataluña. Explicitando los objetivos, metodologías e hipótesis de trabajo, se disecciona su proceso constructivo, particularmente su primera fase, argumentando los fundamentos de una nueva interpretación, de modo que se superan hipótesis precedentes. Atendiendo a evidencias que han pasado desapercibidas, se propone una acotación cronológica para esta fase del edificio ca. 1261-129o. Del mismo modo, se identifican los referentes arquitectónicos de la fábrica de Castelló d'Empúries, que explicitan el currículum formativo del maestro responsable del primer proyecto constructivo, que hay que identificar con Reinald de Chartres. Los perfiles de esta personalidad artística son reconocibles a partir de la comprensión de los detalles más elocuentes y fundamentales de la fábrica. Se establece una perspectiva internacional, desde el gótico rayonnant de mediados del siglo XIII, para la iglesia de Santa Maria, deslindable del resto de la producción arquitectónica catalana del siglo xiII y primera mitad del xiv.

Palabras clave: Santa Maria de Castelló d’Empúries; Reinald de Chartres; Pere Pedrer; proyecto gótico rayonnant; análisis arquitectónico.
\end{abstract}

Aвstract: This study offers a detailed analysis of the church of Santa Maria de Castelló d'Empúries, undoubtedly one of the most original and portentous early Gothic buildings in Catalonia. The main objective of this text is to dissect the construction process of Santa Maria, especially its first phase, according to a methodology that focuses on the material analysis and documentary understanding of the church. Taking into account unnoticed particulars, it argues for a new interpretation that goes beyond previous hypotheses. Through material evidences, this study proposes a chronological estimation of the first project of the building to around 1261-1290, as well as its architectural references. These make explicit the architectural curriculum of the master responsible for the first construction project, who is to be identified as Reinald de Chartres. His artistic personality and technical skills are recognizable from the most eloquent and fundamental facts of the construction. The chronology and authorship of the building represent a significant change in perspective. From the Gothic style of the mid-13th century, an international perspective is established for the church of Santa Maria, which is distinguished from the rest of the architectural production in Catalonia during the 13th century and the first half of the 14th century.

Keywords: Santa Maria de Castelló d'Empúries; Reinald de Chartres; Pere Pedrer; Rayonnant gothic project; Architectural analysis.

\section{- 1. Precedentes historiográficos}

El proyecto arquitectónico inicial de la vigente iglesia de Santa Maria de Castelló d'Empúries,

* Universitat de Girona. Email: gerardo.boto@udg. edu. ORCID: OOOO-0001-5904-5922.

** Agradezco al Ayuntamiento de Castelló d’Empúries, y en su nombre a Jordi Canet Avilés, que me encargaran en el atribulado año 2020 una conferencia pública dedicada a analizar el proceso constructivo de la iglesia de Santa Maria. Estas notas trascriben algunos de los argumentos enunciados en esa ocasión. Las pesquisas se enmarcan en los proyectos Sedes Memoriae 2: Memorias de cultos y las artes del altar en las catedrales medievales hispanas: Oviedo, Pamplona, Roda, Zaragoza, Mallorca, Vic, Barcelona, Girona, Tarragona (PID2019105829GB-Ioo) (AEI/10.13039/501100011033) y Edificis $i$ escenaris religiosos medievals a la Corona d'Aragó (2017 SGR 1724, AGAUR). Agradezco los diálogos desarrollados con los colegas interesados en el magno monumento ampurdanés, particularmente Josep Maria Gironella y Anna Maria Puig. llevado a efecto en la cabecera triabsidiada y los dos primeros tramos de sus tres naves, constituye el único ejemplo del sistema constructivo de gótico radiante (rayonnant) ejecutado en Cataluña. Esa singularidad ha producido en la historiografía tanto interés como perplejidad, hasta el punto de cuestionarse su misma naturaleza y datación.

El proceso constructivo de este templo castellonense ha sido objeto de controversia historiográfica. Como sintetiza Bracons (2002b), en el último tercio del siglo XII las disruptivas propuestas edilicias formuladas en abadías cistercienses (Poblet, Santes Creus y Vallbona de les Monges; Granero 2018), benedictinas (Sant $\mathrm{Cu}-$ gat del Vallès) y en catedrales (Tarragona) introdujeron y propagaron en Cataluña el uso de las bóvedas de crucería. En el paisaje del siglo XIII el empleo de arcos diafragmáticos (Fuguet 1986-87), $\tan$ comunes en las casas bernardas y en la arquitectura doméstica (Fuguet 1998), proliferaron en 
las fundaciones de los mendicantes (Ortoll 1996; Frauer 1999), aunque algunos conventos asumieron el abovedamiento en toda la extensión de iglesias y salas capitulares (Sant Domènec de Girona).

Se ha cuestionado que Santa Maria pueda ser un caso temprano de iglesia gótica pensada para recibir bóvedas de crucería en toda su extensión. Se objeta, de hecho, que pudiera responder a otra tipología, e incluso a otra genética, que la del gótico intitulado meridional o catalán (Freixas 2003: 54). Las últimas aproximaciones al edificio niegan, incluso, la coherencia de ese primer proyecto. Antes bien, justifican que la estructura que observamos es el resultado de balbuceos, rectificaciones, añadidos, interrupciones, atisbos y recosidos (Carrero 2017). Desde esa impugnación, el primer replanteo del edificio no habría generado los arbotantes dobles -insólitos en el paisaje monumental subpirenaico, cualquiera que sea la cronología que se les quiera atribuir, solo compartidos por la Seu de Manresa-, ni habría formulado un presbiterio mayor con un espacio eclesiástico único, ni concibió y elaboró los pilares cilíndricos bajos. Freixas ha supuesto que ni un rasgo ni otro eran asignables a la mano de un maestro de obras llamado Reinald (o Reinaud) de Chartres. El mismo autor ha aseverado que el inicio del proyecto de Reinald no pasó de «puntual o simbólico». Para Freixas la referencia documental no era suficientemente elocuente; ${ }^{1}$ no obstante, algún mérito debía poseer Reinald para que el contrato le denominara magnificum. Freixas (2003: 54) concluye que las obras solo fueron «reformas y ampliaciones» sin ambición, restringidas por la conservación de la iglesia románica. Se niega así el valor acreditativo del contrato público que en 1261 le extendió el notario condal castellonense - en nombre de la comunidad y autoridad condal de Ponç Hug IV (1230-1269) - para que operase una nueva fábrica. Esa interpretación, aquejada de reticencias, niega que se hubiera comenzado a reemplazar la iglesia precedente por una nueva antes de la conclusión del siglo XIII. Además, se ha dado por sentado que

1. «Idus februarii anno domini 1260 fuit inceptum opus novum conficiendi Ecclesie beate Marie Castilionis per magnificum Raynaldum de Xartres cum instrumento publico, facto Castilione Dorquerii condam notario Castilionis, confecto die et anno prefatis». Notula in libro Petri Perrini. Notaries de Castelló d'Empúries, vol. 30 (Freixas 2003: 54). el edificio gótico habría visto condicionado su desarrollo por la preexistencia de la recia torre y de las dos sacristías, la vieja y la nueva. ${ }^{2}$

Los juicios previos impidieron la comprensión de la realidad histórica y tectónica de la fábrica. La exploración material prueba que ni un solo sillar románico puede reconocerse en ninguno de esos ámbitos. Tampoco existe ninguna evidencia de que el edificio gótico se desarrollase restringido ni coartado por las dimensiones y morfología del edificio consagrado en 1064. Lejos de todo ello, el proyecto, que se operó ex novo, observó los criterios del gótico septentrional formulado en abadías e iglesias parroquiales de Eure y de Île-de-France, al margen de las grandes estructuras catedralicias. El diseño planimétrico y la disposición espacial de ese programa constructivo inicial no se limitó a la erección de los ábsides laterales, ni planteó un proyecto de ábside central con un abortado deambulatorio definido por una corona de pilares. La materialidad del edificio desmiente radicalmente esa interpretación. Nuestra metodología se atiene a la exploración de la fábrica para reconocer las evidencias físicas de los proyectos espaciales formulados, de los sucesivos impulsos constructivos y de las rectificaciones y substituciones introducidas en cada uno de ellos.

\section{$\rightarrow$ 2. Punto de partida: estadios históricos precedentes}

Es muy poco lo que se sabe de las dos primeras iglesias de Santa Maria de Castelló d'Empúries. La primera constancia documental de la existencia de un edificio de culto dedicado a Santa Maria en la población de Castelló d'Empúries se remonta a 1007 (Marqués 1977: 20-22; Badia 1978: 95). Poco después, en 1019, ese templo, con sus diezmos, primicias y alodios, había sido cedido ya a la canónica de Girona (Marqués 1977: 23). Nada

2. Durante décadas se arguyó sin justificación probatoria que la torre era anterior al proyecto gótico. Badia (1978: 99-100) la juzgó obra epigonal de la iglesia románica, y otro tanto señala para ambas sacristías. De esa opinión participó Carsalade (1992: 159). También Freixas (2003: 54 y 57) suscribe las tesis del reaprovechamiento de aisladas e injustificadas salas «románicas» y la negación de un proyecto edilicio gótico. Para Carrero (2017: 338) la torre corresponde a la obra gótica y descarta que las sacristías sean románicas. 
se puede aseverar hasta ahora sobre la exacta ubicación y los perfiles de esa iglesia primigenia. Es plausible que no se encontrara en un lugar distinto de donde se erigió una nueva y más capaz iglesia de Santa Maria, en los tiempos del apremiante conde Ponç (1040-1078).

Esa segunda iglesia fue consagrada el 9 de septiembre de 1064 por el obispo Berenguer Guifré de Girona y su corporación canonical en presencia de la condesa Almodis de Barcelona y se dotó de una excepcional área de setenta pasos alrededor, cuando lo habitual en la región eran treinta (Marqués 1977: 26-28; Freixas 2003: 53); el sector meridional de ese atrio se empleó como cementerio desde el mismo siglo XI. Cabe suponer que el edificio respondía a los procedimientos, al léxico constructivo y a la articulación topográfica característicos del primer románico, con muros con resaltes internos y externos para propiciar la recepción y apeo de arcos y bóvedas. Las indagaciones arqueológicas desarrolladas en el entorno de la iglesia han exhumado estructuras murarias y silos, sin detectar por el momento testimonios de un edificio cultual. En cambio, hay indicios de una construcción enigmática en el seno de la nave mayor conforme a las exploraciones de georradar realizadas por el equipo encabezado por Anna Maria Puig. Por el momento no se puede confirmar que esa fábrica corresponda a la iglesia románica, substituida por la superlativa iglesia gótica que aún hoy preside el perfil urbano de la villa condal ampurdanesa. En todo caso, serán las excavaciones arqueológicas en el interior de la iglesia gótica las que podrán confirmar la presencia, ubicación y morfología del templo de 1064 .

\section{- 3. Institucionalidad de la nueva fábrica}

Las mayúsculas dimensiones de este anchuroso edificio - solo la nave central mide $66 \mathrm{~m} \times 14 \mathrm{~m}-$ con esbeltos pilares cilíndricos (Lavedan 1935: 177; Torres 1952: 204; Freixas 2003: 56-57) y la documentada implicación institucional y económica de los miembros de las dos casas condales ampurdanesas y de los próceres locales han inducido a sucesivos autores a considerar, no sin razón, que con esa nueva arquitectura la universidad de Castelló pretendió denotar su afán por recuperar la condición episcopal que había poseído Ampurias en los siglos vi y viI. Aquella sede, como Egara, no había vuelto a ser restablecida tras la recuperación cristiana del territorio en 780 , lo que favoreció la extensión diocesana de la sede de Girona. La iglesia castellonense de Santa Maria fue consagrada en 1315 o 1316 por el obispo Bernardo de Rapolla - Marqués (1977: 38) infiere que por autorización del obispo Guillem de Vilamarí-, hecho que no puede haber sido ajeno a la fundación de la nueva catedral gótica de Girona en 1312, si es que no vino propiciado por el desarrollo de esa nueva empresa episcopal. Muy poco tiempo después de la consagración se fundó la curia eclesiástica castellonense, el 27 de julio de 1317 (Marqués 1977: 37). Ese colegio siguió vigente hasta 1474, momento de su disolución. A lo largo de ciento sesenta años parece haber estado latiendo la aspiración de Castelló d'Empúries de devenir en sede episcopal. No obstante, esa ambición se expresó de manera más determinante con la solicitud elevada por el infante-conde Pere I (1325-1341) al papa Juan XXII a partir de 1331 (Torrent 1976: 225; Genís 2002; Conejo 2016). El pontífice aviñonés atendió la reivindicación y autorizó la erección de la sede ampurdanesa, siempre y cuando el obispo gerundense concediese esa nueva situación. Evidentemente, el requerimiento no prosperó ni entonces ni después.

\section{$\rightarrow$ 4. Materialidad pétrea}

Como han acreditado estudios técnicos (Fumanal \& Gironella 2018: 73), casi toda la fábrica está elaborada con piedra volcánica de Vilacolum (traquita), cuyas canteras se encuentran a once quilómetros en línea recta de Castelló d'Empúries. Ese empleo pone de manifiesto la prodigalidad de las extracciones de traquita, así como la gestión adecuada del transporte terrestre y quizá acuático, por las lagunas y los cauces. En todo caso, esa piedra desbastada fue empleada en el siglo xIII, al menos, en Peralada para algunas partes del claustro de su canónica de Sant Agustí, conocida después como Sant Domènec de Peralada. En Santa Maria de Castelló se contrató también bloques de mármol en 1294, a lo que aludiré más abajo, y fustes de calcárea blanca de Figueres para decorar los niveles superiores de la torre, conforme a la documentación exhumada por Gironella (2017: 36). 


\section{$\rightarrow$ 5. El nuevo paradigma constructivo}

La volumetría y morfología del ábside mayor de Santa Maria ha sido comparada con la de otras cabeceras poligonales del primer gótico del territorio gerundense: la del convento de Sant Domènec de Girona y la de Santa Maria dels Turers de Banyoles (Fumanal \& Gironella 2018). Hasta ahora no se ha establecido una prelación cronológica entre estos edificios.

El convento dominico gerundense recibía donación inmobiliaria en 1252 del terreno que ocupó durante siglos, cedido por el obispo y antiguo fraile dominico Berenguer de Castellbisbal (1252-1254) (Barraquer 1906; Freixas 2002; Molina 2011: 167). Diferentes noticias, a pesar de su carácter impreciso, permiten interpretar que la fábrica conventual -iglesia, claustro y oficinas - fue acometida durante la segunda mitad del siglo XIII, aunque no puede precisarse exactamente en qué cronología. Por su parte, la cabecera de Santa Maria dels Turers puede haber sido ejecutada entre la última década del siglo xiII y la primera del xiv, a tenor del reciente estudio de Freixas (2018), quien interpreta que bajo la dirección del maestro Pere Pedrer de Torroella de Fluvià (1293-1305/1310) se construyó el ábside mayor y el primer tramo. La morfología del presbiterio y de sus contrafuertes rectos de arriba a abajo, la articulación estructural de las nervaduras y el léxico arquitectónico de las ventanas de la iglesia de Banyoles son completamente análogas a las del convento gerundense. Resulta poco plausible, en consecuencia, considerar que entre un proyecto y otro hubieran transcurrido cuatro décadas. Antes bien, ambos proyectos debieron ejecutarse en el mismo arco cronológico. Por ende, descarto que la cabecera dominica de la capital pueda fecharse antes del último cuarto del siglo XIII.

En el presbiterio mayor del templo castellonense se emplearon contrafuertes ataludados, decrecientes en altura. Los vanos, que se abren en todos los lados del hemidecágono y en los consiguientes muros de delimitación de la nave central, están enmarcados en su cara externa por columnas acodilladas en los ángulos de los contrafuertes correspondientes; tales columnas rematan en una arquivolta en la parte superior del paño respectivo y, en dos casos, reposan so- bre ménsulas con forma de cabezas humanas, frecuentes en la plástica monumental gala. Esta sutil solución plástica no se encuentra en ninguna otra iglesia de la diócesis de Girona y, por lo tanto, no puede haberse derivado de un proyecto oriundo anterior, sino que su origen solo puede ser foráneo. Esta constatación no acredita necesariamente que la fábrica castellonense precedió a las cabeceras de Sant Domènec de Girona y la dels Turers de Banyoles, pero desde luego refuta que sea subsidiaria de ellas. La tasación histórica del inicio de las obras en 1261 no encontrará ninguna objeción en las cronologías que se quiera asignar a los procesos de los otros dos edificios.

En Santa Maria de Castelló la cabecera y los dos primeros tramos de las tres naves corresponden a un proyecto constructivo explícitamente distinto del segundo plan, que se desarrolla desde el tercer al octavo tramo, el que se cierra con el hastial de poniente. La concepción de este segundo proyecto de Santa Maria se ha explicado, justificadamente, en el contexto de la arquitectura catalana de la primera mitad del siglo XIV, que se extendió desde Barcelona, Cervera, Girona y Manresa entre 1298 y 1340. Falta justificar, en cambio, en qué experiencias tectónicas y espaciales se inspira el primer proyecto, ajeno a la cultura arquitectónica vernácula.

El interrogante que se plantea pivota en la relación de autoría intelectual y mecánica entre ese singular primer proyecto y la documentada contratación de Reinald de Chartres. El segundo maestro contratado, conforme a la documentación exhumada, fue magister Petrus Petrarii de Torroella de Fluvià en 1305. Ponç Escarrer i Arnau Cavaller, obreros de la obra nueva de la iglesia de Santa Maria de Castelló, encargaron la dirección de las tareas de edificación al maestro Pere Pedrer (Gironella 2017: 20-21; Sais 2017: 15; Fumanal \& Gironella 2018: 87-88). Queda descartado, por tanto, que el maestro Pere pueda ser el autor del primer proyecto de Santa Maria de Castelló d'Empúries, y no solo porque las soluciones de esta fábrica sean ajenas a las estructuras que él mismo construyó desde 1293 en Santa Maria dels Turers de Banyoles (Constans 1987: doc 427; Fumanal \& Gironella 2018: 71). Como demostró Freigang (1992; 1995a; 1995b; 2002a; 2002b), en la segunda y tercera década del siglo XIV en el 
área gerundense el foco de referencia en la arquitectura vanguardista fue la lonja catedralicia de Narbona. Puesto que en Castelló no se aprecia la impronta de la sede languedociana, a diferencia de lo que se consumó en la catedral de Girona, puede descartarse que el primer proyecto de la iglesia ampurdanesa surgiera en el horizonte cronológico de 1300-1320. Ese plan inicial de Santa Maria fue ideado antes de que Pere Pedrer fuera asalariado en Castelló, pero también con anterioridad a su contratación en Banyoles en 1293. Pedrer se nutrió de la tesitura creativa que se había desplegado en Castelló, y no a la inversa.

Para confirmar o descartar que ese primer proyecto pueda ser atribuido a Reinald de Chartres, corroborando si su antroponímico posee o no algún valor indiciario, es requisito perfilar su currículo formativo y su personalidad artística. Los procedimientos constructivos y las formulaciones espaciales del primer proyecto denotan necesariamente el bagaje arquitectónico y las propuestas de disposición topográfica aportados por su autor, quien quiera que fuese. La ecuación se comienza a despejar cuando técnicas y trazas pueden ser identificadas como originarias de un territorio artístico determinado.

A este propósito, resultan elocuentes los contornos de los vanos de la caja de escalera de ascenso a las partes altas de la torre. Construida en el perfil norte de la nueva iglesia gótica, se alzó inicialmente como un prisma aislado, con tres vientos al exterior. Para integrarla en la fábrica de la iglesia, el volumen del husillo recibió inmediatamente una pilastra y un arco perpiaño en el frente de mira a la nave del Evangelio y asumió el engarce de bóvedas en los costados este y oeste, que cubrieron unas inopinadas capillas laterales. Así, la caja de escalera quedó situada en la intersección entre el segundo y tercer tramo de la nave norte. Las dos ventanas abiertas para iluminar el husillo, útiles cuando el elemento en un principio no estuvo insertado en la iglesia, se manifiestan al exterior como saeteras, pero al interior están definidas como vanos verticales con un perfil superior de dintel entre talones. Este diseño, que era ajeno a la tradición nativa, se empleó también en las dos ventanas practicadas en los muros construidos para cerrar y habilitar la llamada «sacristía vieja».
Ese tipo de adintelado de vanos se encuentra en algún edificio construido en el norte de Francia en el segundo tercio del siglo XIII, durante la expansión del gótico rayonnant. Se constata en la iglesia abacial de Saint-Pierre de Chartres (Héliot \& Jouven 1970-71; Thiébaut 1972: 61; Bony 1983: 121 y 484; Kimpel \& Suckale 1990: 255 y 350), conocida antes de la Revolución como SaintPère-en-Vallée. Sus pasajes bajo los contrafuertes externos y el triforio que envuelve tanto el presbiterio mayor como los cinco primeros tramos de las naves presentan esa tipología de vanos; la fórmula fue empleada en la catedral chartriana solo en algunos de los contrafuertes de la nave de la Epístola, pero no en el resto del edificio, ejecutado una generación antes que la abacial. En la fábrica de Saint-Pierre, además, la ampliación oriental de la capilla central del deambulatorio ${ }^{3}$ y la modificación de soportes del presbiterio mayor, llevadas a cabo aproximadamente entre los años 1240-1260, asumieron columnas adosadas y nervios de bóvedas con una sección muy singular -nervio apuntado, con medio bocel seguido de media caña-, con impostas reducidas a un bocel con esa misma sección. Tal solución gráfica, infrecuente en el Eure pero empleada también en distintos edificios languedocianos de la generación de 1240-1270, es la que presentan los nervios y columnas de los ábsides laterales de la iglesia castellonense (Sant Joan Baptista y Sant Llorenç, respectivamente). También la morfología de los capiteles apunta a una genealogía ultrapirenaica, del norte y del Languedoc (Carsalade 1992: 160 y 164). Además, en los absidiolos de Santa Maria las basas de las columnas adosadas en cada ángulo se realzaron sobre pedestales prismáticos análogos, aunque simplificados, a los empleados en Saint-Pierre de Chartres para elevar el inicio de las columnas adosadas en su presbiterio mayor. El edificio ampurdanés, sin embargo, no da cuenta de la proyección vertical de tres niveles presente en la iglesia abacial chartriana y en toda la estela de las grandes catedrales francesas, puesto que en ningún momento se planteó la inserción de un triforio en el presbiterio de Santa Maria.

3. La única publicación monográfica es consecuencia de las reformas ornamentales efectuadas en las décadas centrales del siglo xix: Durand (1864). 


\section{$\rightarrow$ 6. La edificación del proyecto de Reinald de Chartres}

Las aproximaciones más recientes a la iglesia de Santa Maria siguen reconociendo la dificultad de determinar qué sectores de la misma fueron alzadas conforme al diseño y la dirección del maestro Raynaldum de Xartres. Antes de delimitar el alcance efectivo de esta obra, debe advertirse una circunstancia - que también resultó un condicionante - en la concreción física de la propuesta arquitectónica. Del mismo modo que desde el primer momento y a lo largo de todo el proceso se recurrió a la piedra local de Vilacolum, el maestro extranjero tuvo que contratar a oficiales de cantería de l'Empordà como el identificado por Fumanal \& Gironella (2018: 73). Debe atribuirse a esa primera generación de picapedreros oriundos que comenzaron a edificar la fábrica gótica no solo la elaboración y aparejamiento de los bloques con su técnica y procedimiento, sino también la proposición estructural y plástica de algunas partes del nuevo edificio, como el campanario.

Este baluarte, construido en el marco del proyecto de Reinald, nada debe a formulaciones foráneas. Por el contrario, prolonga y actualiza la concepción autóctona de una torre de iglesia, ejemplificada un siglo atrás en Sant Miquel de Fluvià. Los operarios de Torroella o de Vilacolum replantearon y ejecutaron el cubo en coordinación con el plan del maestro francés, pero sin integrarse en él, al menos en los primeros compases. Reinald, que inició su obra por los tres ábsides, estableció un compromiso entre su forastera cultura arquitectónica y la que poseía la comunidad autóctona que le contrató. Mediando entre las propuestas septentrionales y las expectativas meridionales actuaron los operarios ampurdaneses, a los que se les permitió - o acaso, se les instóque construyeran la torre conforme a su tradición propia. Se edificó alineada con el futuro paramento septentrional de la iglesia, pero exenta en sus cuatro costados - como, entre otras, la torre de San Esteban de Gormaz, en origen-, como acreditan dos evidencias: el resalte ataludado en las hiladas inferiores presente en el perímetro exterior de las caras este, norte y oeste - esta última forrada en el segmento murario que se aprovechó para delimitar la capilla de Sant Jordi- y la inexistencia original de pilastras para apear los arcos perpiaños y cruceros de la nave contigua, pilastras añadidas cuando el cuerpo de la torre había alcanzado ya media altura. Desde un inicio en su seno se habilitó un espacio de planta cuadrada que tuvo vocación de capilla particular, ${ }^{4}$ probablemente para alojar el altar de Sant Nicolau transferido desde la capilla homónima para la que el conde Hug IV (1200-1230) en 1219 había fundado de su propio pecunio un beneficio dentro de la pretérita torre románica (Marqués 1977: 34 y 59; Cobos, Tremoleda \& Vega 2010: 38). No puedo descartar que ese campanario precedente - que no fue reutilizado en la nueva iglesia, como sí sucedió en San Saturnino de Artajona o mucho más tarde en la catedral de Vic- se encontrase en las inmediaciones de la torre gótica; y no es desafuero especular que se empleara como andamio para facilitar el progreso de esta última a finales del siglo XIII.

Los ábsides laterales presentan planta hemidecagonal, sin tramo recto, directamente abiertos a los respectivos tramos iniciales de las naves del Evangelio y la Epístola. De los cinco paños, el central presenta vano perforado con dos lancetas y trébol, y el contiguo una tracería ciega, que en el ábside meridional de Sant Llorenç acabó abierta cuando se alteró por completo ese lienzo en época moderna. Las proporciones de los absidiolos es aproximadamente una sexta parte de la extensión en planta - no digamos ya en volumen- del presbiterio mayor. Esta disparidad espacial no resulta de diferentes ideaciones o de enmiendas sobrevenidas. El examen de los muros perimetrales del ábside central no delata incongruencias ni vacilaciones en el proyecto edificatorio. Cuestión distinta es acreditar en qué episodios y por qué causas se introdujeron soluciones y recursos en forma de capillas privadas cementeriales, que modificaron las atribuciones funcionales y es-

4. Ese espacio interior supone el $50 \%$ de la superficie de la planta total de la torre, proporción que ya se había observado en la torre de Sant Miquel de Fluvià, pero no en las torres de las catedrales de Vic, de Girona o de la abadía de Canigó, por señalar algunos ejemplos de baluartes edificados al norte de la iglesia.

5. Desde Sant Martí del Canigó o la catedral de Vic (o de otro modo en Sant Pere de Rodes) hay capillas dentro de las torres románicas, dedicadas al Sant Sepulcre y a Sant Miquel. En Santa Maria el beneficio dedicado a Sant Nicolau en la torre románica se trasladó a la torre gótica. 
cénicas del espacio ceremonial y de sus ámbitos anejos.

Los siete paños del ábside mayor presentaban en su nivel inferior un banco corrido de tres hiladas, que pudo ser utilizado por una parte de la comunidad reglar en algunos de los oficios. Sobre el banco arrancan sendos arcos ojivales ciegos. Los cinco - o seis, según el arco en cuestiónprimeros sillares de cada uno de estos arcos, que no son dovelas aún, sino que proporcionan la proyección vertical de los arcos, se montaron enjarjados con el arco contiguo y con la columna adosada que resalta y sella las inflexiones angulares del polígono del presbiterio; las basas de esas columnas integradas se encuentran exactamente niveladas con el pavimento, lo que revela que la edificación de los muros consideró en qué cota se asentaría el suelo empedrado. Esas basas de las ocho columnas se encuentran severamente erosionadas, pero puede reconocerse que sus perfiles son similares, sino idénticos, a los de las basas de las columnas adosadas de los ábsides laterales. Por encima del banco de fábrica, las siguientes cinco hiladas de cada lienzo presentan la misma dimensión y fueron aparejadas al tiempo que los sillares verticales de los arcos y los tambores de las columnas adosadas. Esa coherencia continua en las hiladas correspondientes a los salmeres y, en algún paño, incluso en la hilada que se corresponde con las segundas dovelas de los arcos ciegos.

Esta disposición original se vio alterada en el segundo paño del flanco septentrional por la apertura del acceso a la llamada sacristía nueva y en los tres costados más orientales del presbiterio por la supresión de los muros respectivos para habilitar otras tantas capillas funerarias, que alcanzaron su límite vertical en el alféizar de los ventanales superiores.

La conclusión es inequívoca: nunca se planteó otra articulación del muro perimetral del ábside mayor, ni se han suprimido elementos que hubieran estado. En consecuencia, las columnas simples, adosadas y enjarjadas solo podían recibir en altura un nervio único que convergiese con los otros siete para formar la bóveda de paños triangulares y clave única. En ningún momento se acometió una fórmula constructiva distinta, con terceletes o nervios cruceros.
Desde las dos sacristías, la vieja y la nueva, pueden reconocerse las caras externas de los muros del polígono y la definición constructiva de los contrafuertes, que son solidarios y congruentes con esos muros en todo su desarrollo. La proyección vertical de los muros y de los estribos no se advierte interrumpida en ningún nivel, sino que responden a un impulso constructivo constante y sostenido. Solo se observan alteraciones en la definición de los alféizares y costados de los grandes ventanales que centran las partes altas de cada lienzo. Cada uno de esos vanos presenta rectificaciones en los sillares del contorno horizontal y en las cuatro o cinco primeras hiladas de los flancos. Eso significa que en un primer momento se habían planteado vanos de dimensiones sensiblemente menores y que la fábrica se detuvo para ensanchar la luz de los mismos. No obstante, en el momento en que se efectuaron esas enmiendas, el prisma del presbiterio estaba ya completamente definido y su estructura ya había sido aparejada para culminar su cubrición y entrar en carga. Cuando salga a la luz la documentación referida a la elaboración de los ventanales se podrá acotar una cronología absoluta para la secuencia relativa que aquí se enuncia. Ya Gironella (2017: 20) reveló los nombres de algunos maestros vidrieros, de origen francés, que trabajaron en la cabecera de Santa Maria en torno al año 1300. Esos contratos sugieren que ya estarían ejecutados tanto los perfiles de las ventanas como los muros altos que las alojan.

De los siete costados del presbiterio mayor, en origen solo el segundo del costado sur contaba con una puerta, mientras los seis muros restantes recibieron los mencionados arcos ciegos reposando sobre el banco corrido. Esa puerta presenta un arco carpanel en el flanco que mira al altar y un arco escarzano en el contrario; este perfil, por cierto, también fue asumido por el acceso lateral de la nave del Evangelio. En esa puerta el codillo donde se alojaron los pernios de las hojas de madera se sitúa en el costado externo. Las cavidades para hincar los travesaños se encuentran también en ese lado exterior. Sin embargo, no puede aseverarse en qué momento fueron practicados. En un primer y pasajero momento esta puerta conducía a un exterior descubierto, particularmente al área cementerial (Ribas 20o1b: 17) que 
se extenderá desde este extremo hasta la capilla cementerial de Santa Maria l'Antiga que, como es sabido, fue destruida por la construcción de la capilla de Nostra Senyora dels Dolors, concluida en 1777. Cuando ya estuvieron edificados la puerta, el muro y los contrafuertes hasta la altura de los ventanales - al menos treinta hiladas de sillares-, así como los ábsides laterales, se decidió inmediatamente que el espacio preliminar al ingreso deviniera en la cámara de planta trapezoidal que aún conservamos hoy. Para ello, se construyó un cierre mediante tres muros perpendiculares cuyos extremos entestan en el perfil vertical de los contrafuertes. De esos tres nuevos muros, el oriental y el meridional se proveyeron de una ventana oblonga, con un perfil superior en cortina idéntico al de las ventanas de la caja de escalera antes mencionada. A la estancia se le añadió al oeste un zaguán exiguo dotado de un lucernario para iluminar la ventana del absidiolo de Sant Llorenç, puesto que el altar del mártir quedaba privado de luz rasante por la inopinada clausura de ese recinto destinado a sacristía. La adaraja de este añadido a la preexistente fábrica del ábside de Sant Llorenç (Marqués 1977: 69; Cobos, Tremoleda \& Vega 2010: 41) es visible también desde la cámara auxiliar de la capilla dels Dolors. La nueva sala, llamada a cumplir las funciones de sacristía y así se la denomina aún hoy, fue cubierta con una bóveda de crucería simple, que reposa sobre nervios cuya elemental sección - definida por un listel plano entre dos cavetos simétricos- no se encuentra en ninguna otra parte de la basílica de Santa Maria. La gráfica de esa sección acredita su temprana cronología en el decurso histórico de la fábrica.

Resulta desconcertante que, al replantear los cimientos de la iglesia, no se hubiera previsto la habilitación de la imprescindible dependencia auxiliar que custodiara el ornamento litúrgico y alojara el revestimiento de los celebrantes. Solo cabe una explicación: dado que la puerta que permite el acceso a esta sacristía está constituida por sillares que prolongan las hiladas del lienzo, se infiere que el maestro de obras concibió y calculó desde un origen que ese vano daría paso, cuando correspondiese, a un ámbito auxiliar. No obstante, en lugar de aparejarlo simultáneamente, pospuso su construcción al momento en que estuvie- ra ya concluido el cierre del ábside mayor. Para solventar la necesidad apremiante de una sacristía se orquestó la solución elemental pero eficaz de los tres muros perpendiculares que se anclan al preexistente cerramiento murario del presbiterio. La observación de puerta de la sacristía desde el interior de esta, y más en particular del arco escarzano y la parte superior de los montantes, permite advertir evidentes adarajas y saltos de hiladas. Esta corrección es indicio de que ese flanco del vano se llevó a cabo cuando el muro poligonal del presbiterio ya estaba concluido. Los codillos resultantes de esa segunda intervención fueron concebidos para posicionar los quicios de los batientes. En síntesis, se infiere que la dependencia trapezoidal fue edificada post quem la obra de los ábsides - el mayor, al menos hasta los ventanales; los laterales, completos-, pero ante quem la entrada en actividad litúrgica del altar mayor en 1315/1316.

De las dos ventanas de la sacristía, la abierta a levante quedó cegada cuando se construyó la más meridional de las tres capillas radiales del santuario principal. Precisa Gironella (2017: 19) que en 1330 se acordó la construcción de la capilla de la Santa Creu, y a las mismas fechas es atribuible la ejecución de la capilla axial, la de Santa Úrsula, promovida por Ramon d'Empúries (Marqués 1977: 66-67; Freixas 2003: 52; Cobos, Tremoleda \& Vega 2010: 40). La ejecución de las tres capillas sajó el preexistente muro de cierre - que con seguridad también aquí presentaba banco corrido y sobre él arco ojival ciego- - y envolvió los contrafuertes, que son visibles en el fondo de los arcosolios funerarios de la capilla de Santa Úrsula (Gironella 2017: 19). Obviamente la construcción de la capilla funeraria más meridional, de Sant Esteve - probable lugar de enterramiento de Ramon Bou en 1331, fecha ante quem -, no estaba prevista en el momento en que fue habilitada la sacristía; por esa razón la sacristía se dotó de una ventana hacia levante, que quedó obliterada al cabo de tres décadas por la imprevista capilla de Sant Esteve. La evidencia permite establecer también una secuencia cronológica entre las tres estructuras que se trabaron en ese extremo: a) perímetro del presbiterio, b) perímetro exterior del lienzo de la sacristía, y c) plano vertical del lienzo suroccidental de la capilla de Sant Esteve. 
De los análisis murarios se infiere que el colosal ábside mayor se concibió y ejecutó como un espacio único, sin segmentaciones internas ni agregaciones perimetrales. Para articular el espacio celebrativo se adoptó una solución que carecía de antecedentes en la arquitectura medieval en Cataluña. De acuerdo con la documentación recientemente exhumada (Gironella 2017: 18; Fumanal \& Gironella 2018: 86), el 22 de enero de 1294 los obreros de la iglesia de Santa Maria Ramon Malarç y Bernat Paner compraron al maestro de obras Pere Pedrer, de Torroella de Fluvià —es decir, un año después de ser contratado como maestro de la fábrica bañolense y once antes de que se le atribuyera el mismo cometido en la castellonense-, trescientas losas del mejor mármol para la iglesia de Santa Maria de Castelló, que debían ser entregadas en tres meses con un costo total de 105 sueldos. Es evidente que esa ingente cantidad de material prestigioso se empleó en el pavimento del presbiterio mayor (Gironella 2017: 18). ${ }^{6}$ Este enlosado forra decorosamente los dos escalones que separan la nave mayor del presbiterio y que precisan la cota de circulación por el interior del ábside mayor, cota que venía ya prefijada por la posición de las basas de las columnas integradas en los ángulos internos del polígono absidial y por el umbral de paso a la sacristía - otro indicio para acotar aún más la cronología de la definición espacial de esta sala auxiliar: ante quem 1294. Además, parte de esas placas de mármol se emplearon para revestir la plataforma - hemidecagonal en el extremo de levante y probablemente recta en los lados norte, sur y oeste-, originalmente de dos escalones, como se puede confirmar en el peldaño en el que se insertó la rejería. Así, esa plataforma original -modificada en el siglo xviII para realzar y darle el aspecto que presenta aún hoy- mantendría alguna semejanza, mutata mutandis, con la visible aún hoy bajo el altar mayor de la catedral de Tarragona. Ese realce del pavimento, ejecutado en 1294 pero previsto desde

6. De acuerdo con lo conservado, no fue habitual que las iglesias de las diócesis catalanas se engalanaran con mármol. Es de sobras conocido el caso de la iglesia de Sant Pere de Rodes, en el interior y en su desaparecida fachada (Barrachina 1998-99). La retórica del material marmóreo fue más clara aún en la iglesia y en el claustro de la catedral de Tarragona (Boto 2015; Boto \& Serrano 2018). un origen, pretendió conceder mayor visibilidad y dignidad al altar mayor.

La noticia de la compra de mármol se complementa con otra: entre 1295 y 1296 se contrató con el maestro Terrer y el carpintero de Ceret Arnau Riba un retablo y un tabernáculo, ${ }^{7}$ lógicamente para alojar en su seno la imagen de la titular del templo. Ese primer tabernáculo fue rehecho por los hermanos Serra en 1361 (Gironella 2017: 27). El vigente retablo de alabastro fue elaborado desde 1452 (Pujol 1989). La plataforma poligonal, con su superficie blanquecina resplandeciente, su altar y su mobiliario complementario, generó un pasillo perimetral, de solo dos escalones de diferencia, pero muy explícito, más aún que el existente en el ábside mayor románico de la sede tarraconense.

Esa pavimentación se efectuó un lustro antes de que se pusiera la primera piedra de la catedral de Barcelona y doce años antes del inicio de Santa Maria de Cervera (Lavedan 1935: 191-192; Torres 1952: 203). Hacia 1306 se acometió la fábrica de Sant Genís de Torroella, dotada de un ábside con capillas radiales - como Santa Maria de Montblanc o Sant Miquel de l'Espluga de Francolí-, ${ }^{8}$ a las que se accede sin interferir en el espacio presbiteral merced a que este dispone de una plataforma realzada. No me consta documentalmente

7. «"Tabernaculo et reretaule Beate Marie Castilionis" que va fer per manament seu, fet còmput, "Terreno, magistro predicto"», Arxiu Històric de Girona (AHG), Fons Notarial de Castelló d'Empúries (Ca) 16, 19 de gener de 1296 (Gironella 2017: 27).

8. Desde el siglo XI se proyectaron ábsides mayores con capillas radiales. La fórmula se gestó en las lonjas aquitanas del priorato de Saint-Orens d'Auch, la catedral de San Caprasio de Agen, la catedral de Saint-Étienne de Cahors o en la abadía de Caunes-Minervois, entre otros, y fue traspasada a la catedral de Sigüenza por el obispo Bernardo de Agen hacia 1130-1135, como ha demostrado Cosmen (2016). Entre el paisaje arquitectónico catalán, el presbiterio mayor de Sant Joan de les Abadesses ofrece esa articulación, pero como resultado de una accidentada pérdida de su girola. En cambio, la solución de las tres exedras en el muro semicilíndrico se habilitó en Sant Pere de Ponts - perpendiculares-y en la parroquial de Santa Maria de Porqueres - embebidas a ras de paño. Desde el siglo XIII la disposición de capillas tangentes abiertas en el perímetro de un presbiterio poligonal se prodigó en la arquitectura mediterránea (Carsalade 1992: 162). Sin embargo, Castelló d'Empúries no puede sumarse a la nómina puesto que la disposición radial de capillas abiertas al presbiterio mayor no fue una solución proyectada desde un origen, sino sobrevenida, como se detalla más abajo. 
desde cuándo existe esta fórmula en Torroella —nada puede inferirse de los bloques de piedra porque son reposiciones de restauraciones recientes-, pero es obvio que reproduce la solución de Castelló d'Empúries, incluyendo una réplica moderna de la reja perimetral.

La secular solución de los tres ábsides paralelos, que siguió empleándose en el siglo XIII en el centro y norte de Francia y fue reinterpretada en Santa Maria de Castelló, impedía la generación de una girola que arrancara desde el extremo oriental de las naves colaterales, puesto que estas embocaban en los absidiolos. Por ello la solución de la plataforma con su pasillo subsiguiente se acomodó al ancho del presbiterio mayor, como una actualización fásctica de un tipo de disposición

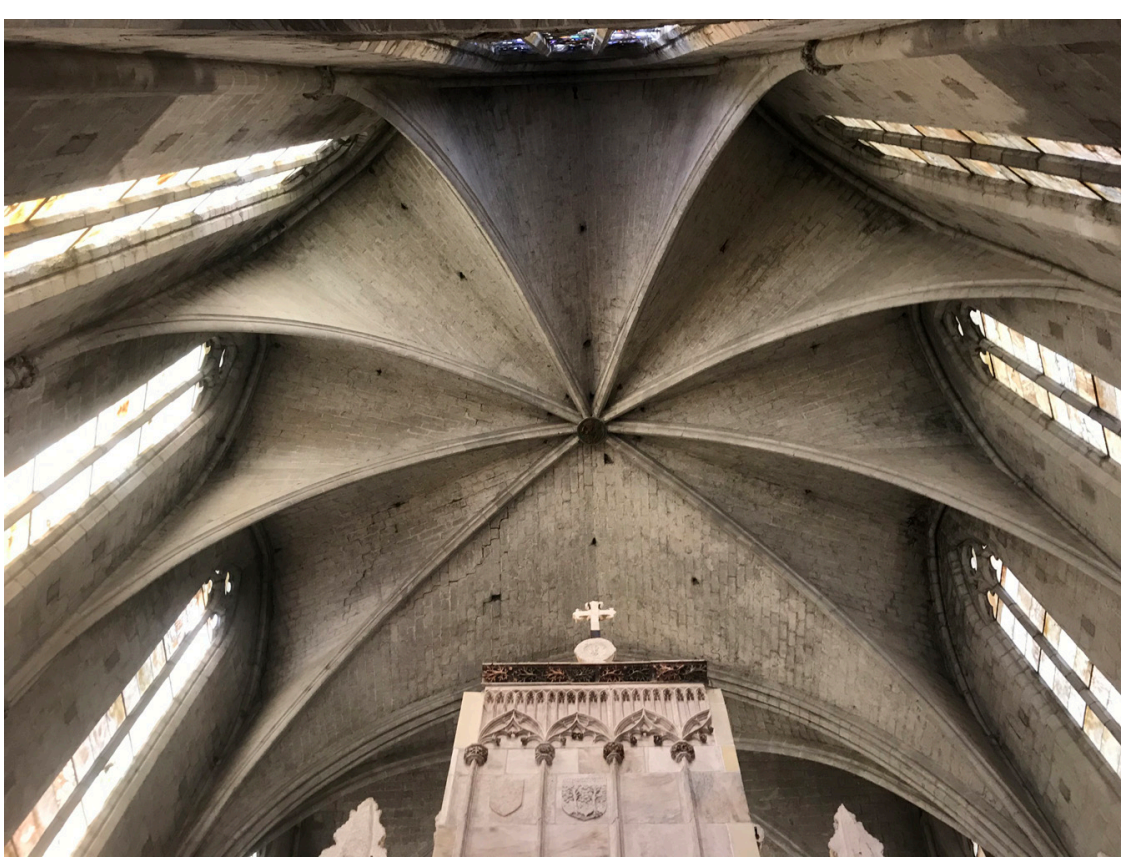

IMAGEN 1 - Bóveda del presbiterio mayor. Foto del autor.

que se había ensayado anteriormente, con diferencias, en Sant Joan de les Abadesses o en Tarragona.

Advertir que el presbiterio fue aparejado con mármol comporta, de modo subsiguiente, el planteamiento de dos cuestiones: una de naturaleza edilicia y cronológica; la otra, de orden funcional y escénico. ¿Cuándo se llevó a efecto el cierre de la bóveda del presbiterio, antes o después de 1294-1295? Es decir, el andamiaje que tuvo que instalarse para llevar a cabo el abovedamiento y permanecer hincado al menos hasta que entraran en carga nervios, clave y plementos (Imagen 1), ¿se asentó sobre el suelo ya revestido de mármol o previamente a la instalación de las losas? O por decirlo de otro modo, ¿los obreros de Santa Maria formularon el encargo cuando, retirado el maderamen, supieron que el costoso material veteado ya no sufriría ningún desperfecto, o acaso solicitaron las placas blancas y brillantes en un tiempo en que nadie se planteaba aún qué fracturas podían ocasionarse en ellas? ¿Razonaron igual en relación con la ejecución del retablo y el tabernáculo en 1295-1296? Imaginar esta segunda opción conlleva atribuir una desconcertante temeridad e inconsciencia a los gestores del edificio.

La respuesta más lógica implica entender que en 1294 estaba concluida toda la estructura arquitectónica del presbiterio mayor, de modo que podía revestirse el pavimento y organizar el decoro visual requerido por el culto en el altar mayor. Habrían transcurrido treinta años desde el inicio de los trabajos inaugurados por Reinald de Chartres. El lapso temporal parece más que suficiente para haber efectuado la elevación de la cabecera, si es que los recursos económicos no sufrieron mengua o dilación. Además, ese horizonte proporciona un contexto coherente para la contratación del pintor y carpintero a finales del siglo XIII y de los maestros vidrieros muy pocos años después.

La segunda cuestión que debe discernirse es la causa que motivó la generación de un pasillo deambulatorio en torno al área sobrealzada para incrementar la dignidad y visibilidad de la celebración eucarística. Recuérdese que en 1294 en la cabecera no existía ninguna capilla ni tumba monumental que requiriese un acceso específico, ni tampoco reliquia alguna que estimulase una visita devocional o solicitase un circuito específico, al margen de las que acabaron instaladas en 


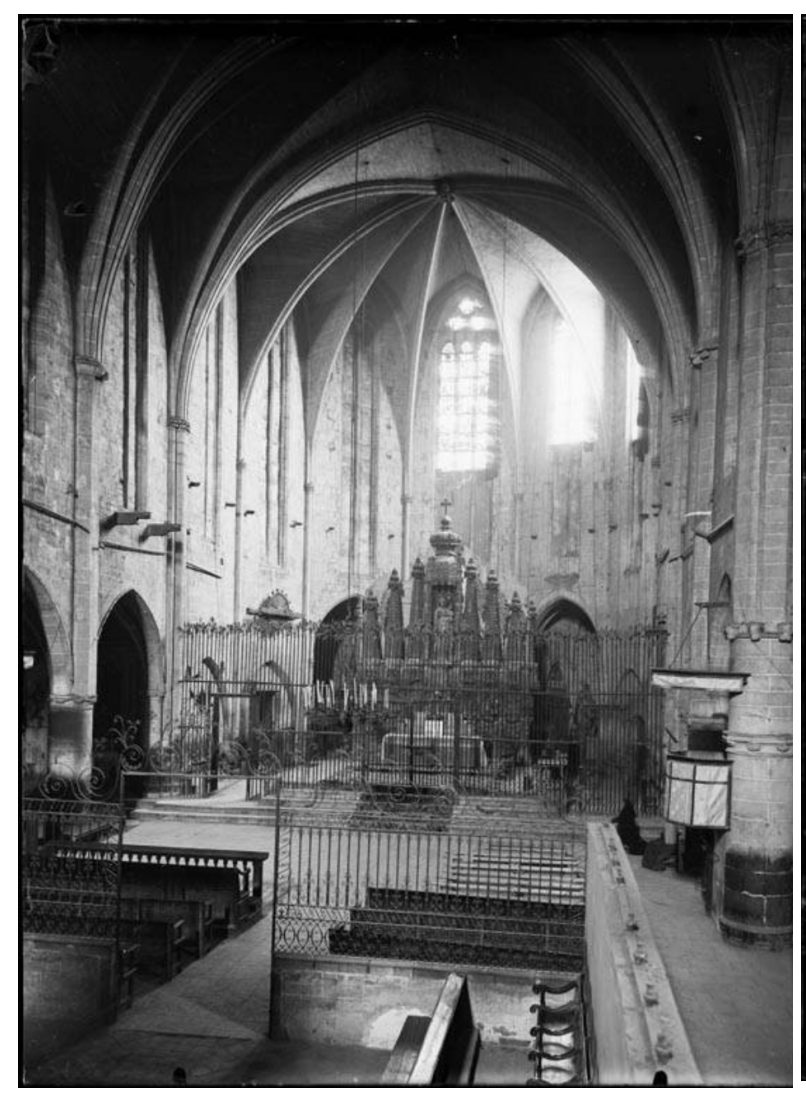

IMAGEN 2 - Altar de la Basílica Santa Maria de Castelló d'Empúries entre 1888 y 1896 (Lluís Marià Vidal, 18421922). Arxiu Fotogràfic del Centre Excursionista de Catalunya (AFCEC VIDAL 18X24 047).

el altar mayor: un fragmento de una imagen de una virgen de Cerdeña llegada en 1307 y reliquias de San Felipe, de Santa Úrsula y las once mil Vírgenes, de un lugar de Belén y de San Mauricio, depositadas en el momento de la consagración (Marqués 1977: 38-39; Gironella 2017: 18). La rejería que clausuró el presbiterio contó con una puerta central dirigida al coro, instalado en el eje de la nave mayor, ${ }^{9}$ (Imágenes 2 y 3 ) y dos pasos menores a sendos lados que permitían embocar el pasillo anular. Por supuesto esta reja se realizó casi dos siglos después de la construcción de las capillas de la Santa Creu, Santa Úrsula y Sant Esteve -y, por tanto, de la instalación de

9. Como señala Gironella, el maestro mayor Pere Trilló certificó diversos gastos del obrero de Santa Maria de Castelló, entre ellos 86 sueldos y 4 dineros para arreglar los sitiales del coro y el tejado («catedras cori et pro recoperiendo tegulatum», AHG, Ca 309, 29 d'octubre de 1369).

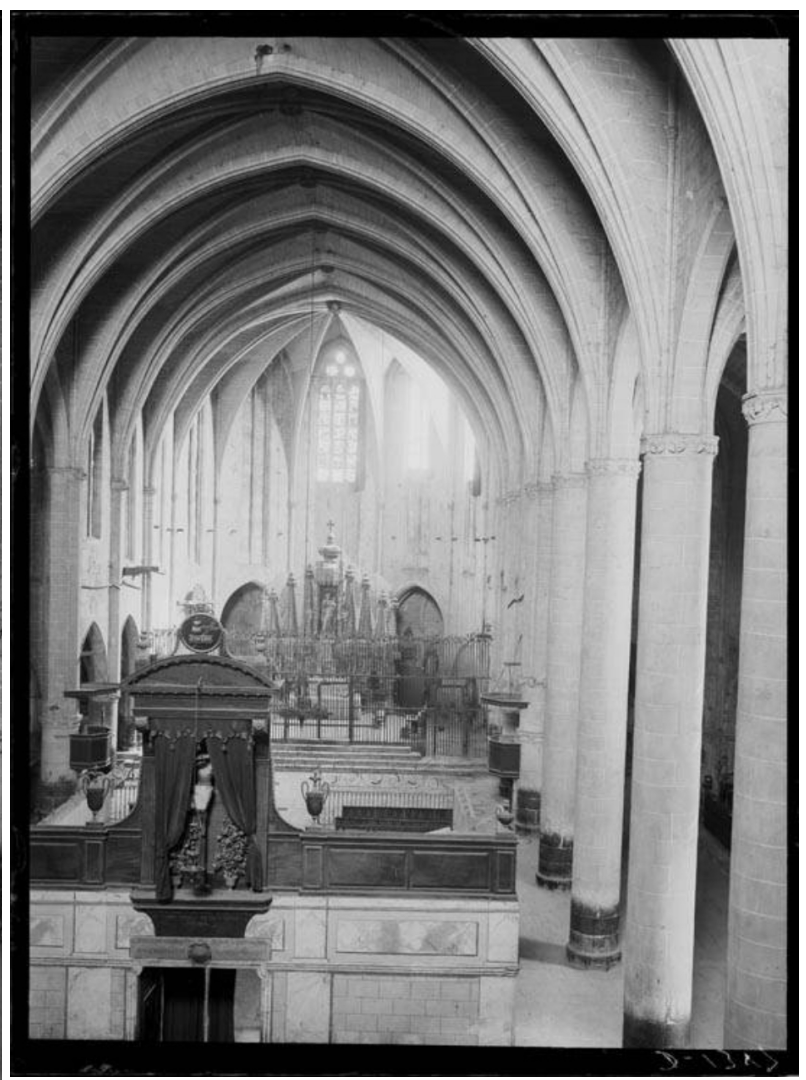

IMAGEN 3 - Interior de la Catedral de Santa Maria de Castelló d'Empúries (Juli Soler y Santaló, entre 1900 y 1914). Arxiu Fotogràfic del Centre Excursionista de Catalunya (AFCEC SOLER ${ }^{*} D V$ 014-00663).

las tumbas que propiciaron su edificación y que exigían un acceso ceremonial hasta ellas. Las rejas de menor altura fijadas en el perímetro de la plataforma presbiteral, de acuerdo con fotografías de finales del siglo xix (Lluís Maria Vidal, 1888-1896) y principios del xx (Juli Soler i Santaló, 1910; Josep Salvany i Blanch, 1912; Carles Fargas i Bonell, ca. 1920; Valentí Fargnoli, 1911-1925; Manuel Genovart, 1922-1931), constituyeron un eficaz y económico recurso para segregarla del pasillo (Imagen 4).

El retablo y el tabernáculo contratado en 12951296 a los maestros Terrer y Arnau Riba dejó un espacio tras ellos, en el ápice oriental de la plataforma. ¿Se situó allí un reservorio, más eucarístico que relicario (Carrero 2017: 345)? ¿Se habilitó acaso un conditorium (Du Cange 1842: II, 522) o un reservatorium (Du Cange 1886: VII, 143)? Por ahora no hay constancia documental ni material de ello. Aunque se trate de una especulación más, 


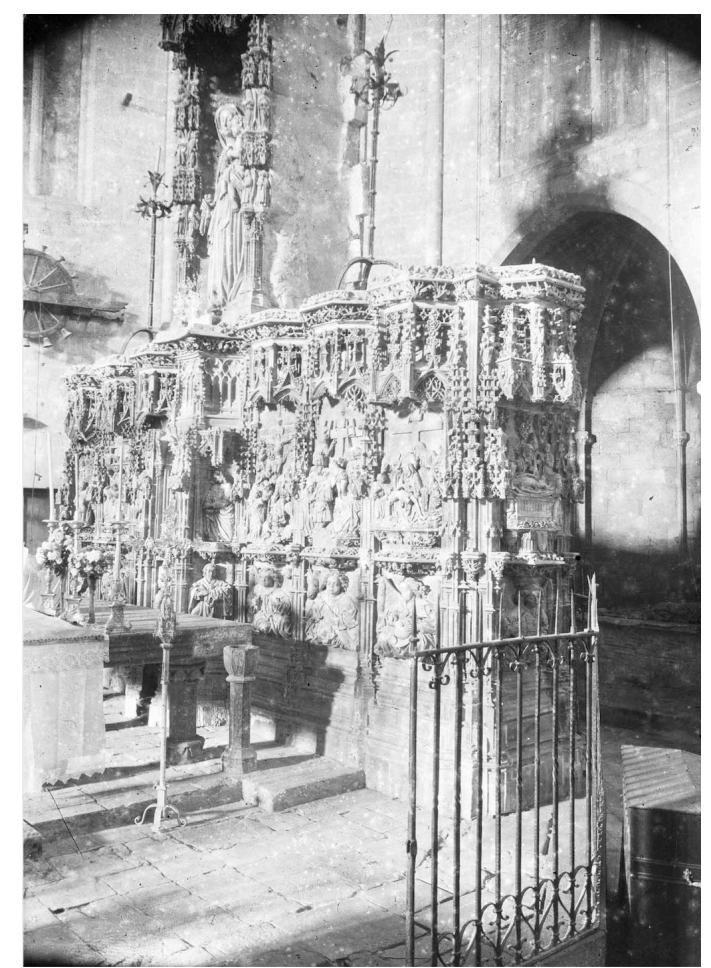

IMAGEN 4 - Vista lateral del retablo y del altar mayor de la basílica de Santa Maria, en Castelló d'Empúries, entre los años 1942 y 1944. Archivo Comarcal de la Garrotxa, Fondo Sadurní Brunet Pi.

no es descartable que ese sector al este del retrotabulum se hubiera imaginado como eventual destino de algún enterramiento privilegiado, en todo caso nunca llevado a efecto.

Conforme a las evidencias materiales, los testimonios que pautan la secuencia constructiva y las referencias documentales no hay objeción alguna para aceptar que la consagración de 13151316 se celebró con los tres ábsides, los laterales y el mayor, completamente construidos, provistos de recursos de articulación espacial y de decoro visual desde el retablo a los ventanales, y con la sacristía concluida y en servicio. Todo ese ambicioso proyecto nació ex novo de las trazas de Reinald de Chartres. En su concepción y ejecución obvió la preexistencia de la iglesia románica de 1064, pero contemporizó con las tradiciones edilicias oriundas en la torre. El maestro Reinald fue contratado para ofrecer un planteamiento novedoso y rupturista. No consta, sin embargo, hasta qué fecha permaneció al frente de la construcción y si décadas después de su llegada contaba con un ayudante ampurdanés que prosiguiera su plan.
No parece plausible que Reinald fuera el único maestro de obras durante los cuarenta y cuatro años que median entre su contratación (1261) y la de Pere Pedrer (1305), pero probablemente sí en las tres décadas que van de inicios de los años 60 a inicios de los años 90 del siglo XIII.

\section{$\rightarrow$ 7. La ejecución de las partes altas de los primeros tramos de las naves}

La cabecera de Santa Maria no precisó la instalación de arbotantes puesto que, al carecer de deambulatorio y de capillas radiales abiertas a este, su perímetro circundante era el propio prisma del ábside mayor. En consecuencia, los empujes de la bóveda podían ser absorbidos directamente por la batería de contrafuertes escalonados (Imágenes 5 y 6) y no estaba justificado emplear otra solución, ni en la Île-de-France ni en Cataluña. En cambio, el intervalo y la diferencia de altura entre los costados de la nave mayor y el cierre de las naves laterales exigió recurrir a apeos aéreos en doble altura. El enteste de los arbotantes contra el muro se produjo por con-

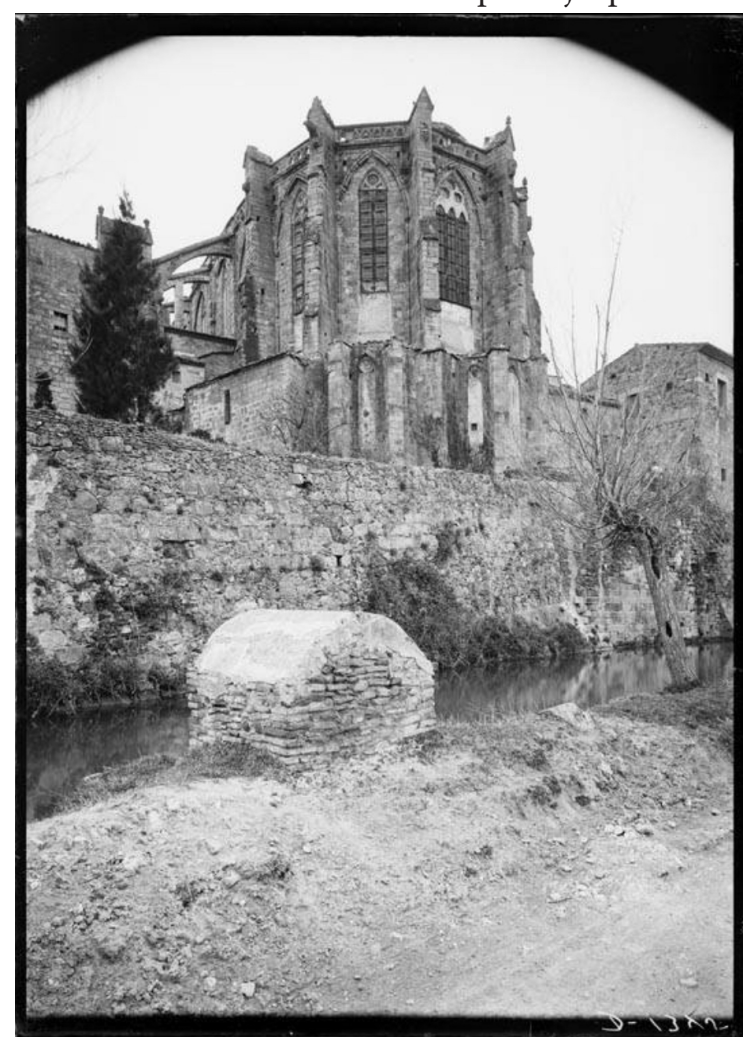

IMAGEN 5 - Ábside de Santa Maria de Castelló d'Empúries ca. 1910 (Juli Soler y Santaló, 1865-1914). Arxiu Fotogràfic del Centre Excursionista de Catalunya (AFCEC SOLER D 1345). 


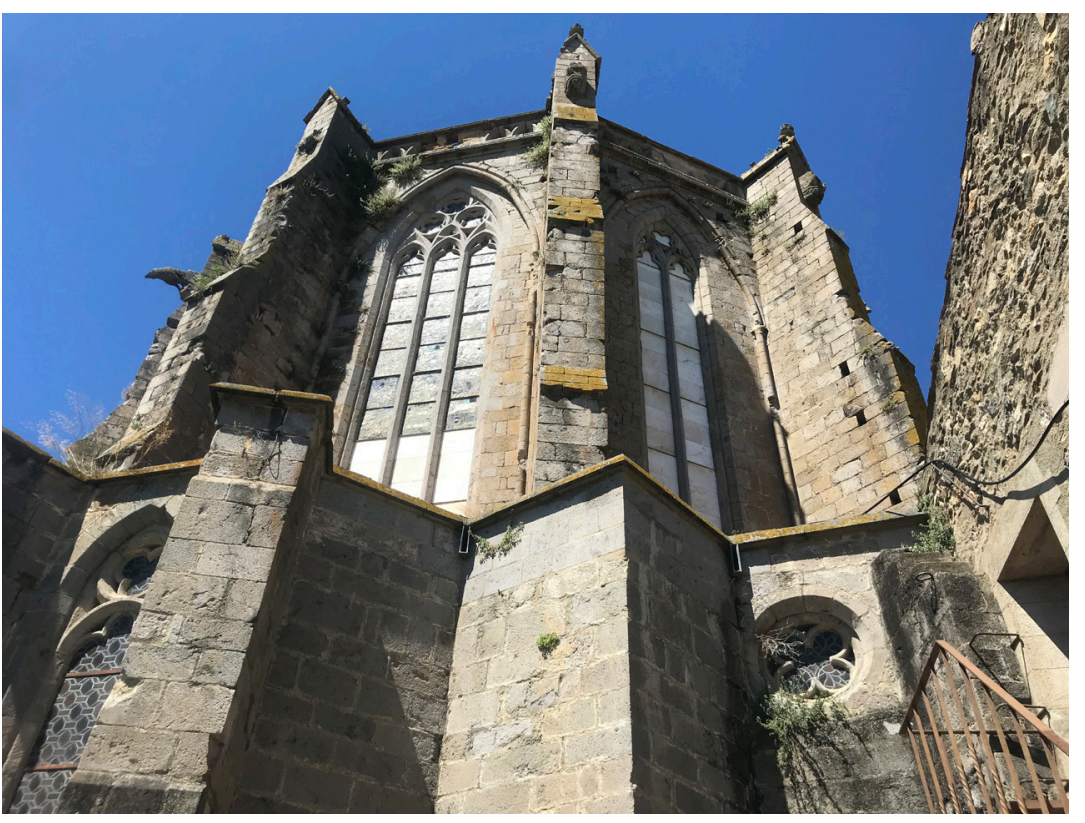

IMAGEN 6 - Ábside mayor de Santa Maria de Castelló d'Empúries. Foto del autor.

tacto y no por inserción. Este procedimiento no fue observado solo en los tramos correspondientes al primer proyecto, sino también en los siete tramos del segundo plan constructivo, tanto en flanco septentrional como en el meridional. Puesto que la solución se revela característica del edificio ampurdanés y de sus sucesivos constructores, en modo alguno cabe concluir que los arbotantes fueron elementos imprevistos en el diseño original de la fábrica ni que son elementos añadidos con retraso; no están rehechos, como se ha querido defender. Se infiere, por el contrario, que el maestro de obras, que había aparejado contrafuertes muy sobresalientes para el presbiterio, consideró la instalación de arbotantes cuando los muros laterales de la nave mayor estaban ya construidos y habrían comenzado a trasladar la compresión generada por la bóveda en carga. Fue una intervención llevada a cabo en dos tiempos, como sucedió en la sacristía.

Como argumentó José Luis González (2007: 479-488), los cuatro dobles arbotantes que se llegaron a construir para transmitir las presiones de la esbelta nave mayor fueron diseñados con errores de cálculo. La altura en la que entestan con el muro y las inclinaciones de los tranquiles son geométricamente incorrectas. Ese error ha comprometido la perduración de los arcos y, de modo sensible, la función mecánica que debían desempeñar.

A pesar de esas deficiencias, no es imaginable que los arcos rampantes y los botareles fueran concebidos $\mathrm{y}$ elaborados por un maestro vernáculo como Pere Pedrer, ajeno por completo a cualquier recurso del sistema tectónico desplegado en el gótico septentrional. En otras palabras, su ejecución tuvo que llevarse a cabo con anterioridad a 1305, quizá varios lustros antes. A mi juicio, está fuera de cuestión que el empleo de estos arcos de transmisión fue propuesto por Reinald de Chartes. Más complejo es determinar quién ejercía la dirección constructiva de la fábrica en el momento de su ejecución y entrada en compresión: acaso el propio autor intelectual o en su ausencia - por defunción o por partida - un colaborador directo. Por decirlo de otro modo, no alcanzamos a saber si la deficiencia estructural de los arbotantes es atribuible a una limitada experiencia de Reinald o al hecho de que este no alcanzó a tutelar su ejecución. En cualquiera de las dos hipótesis, los exóticos arbotantes de Santa Maria constituyen el único y efímero episodio del gótico radiante en la arquitectura catalana. En todo caso, desmienten que la arquitectura catalana fuera genéticamente refractaria al opus francigenum como se ha afirmado (Bracons 2002a: 22).

Mientras se elaboraban los cierres de las naves laterales y se erigían los estribos, se prolongó verticalmente la caja de la escalera helicoidal. El análisis de los paramentos permite confirmar que el husillo fue ejecutado en un único impulso hasta la portezuela que da paso a las cubiertas de los dos primeros tramos la nave lateral baja. El muro de cierre del tercer tramo de la nave septentrional, que corresponde ya al proyecto de las naves laterales altas y los pilares cilíndricos esbeltos, no es solidario con el preexistente prisma de la caja, sino que entesta en él. Sin embargo, el sector más alto de la escalera, que permite salir hacia la cor- 
nisa de la nave lateral y llegar a la única puerta que tienen los pisos superiores del campanario, fue realizado cuando ya se operaba el segundo proyecto arquitectónico. La ratificación material de este proceso se advierte en el lienzo oriental del tercer tramo de la nave del Evangelio, donde se produce el salto de altura de las colaterales bajas a las altas.

Como va dicho, la mayúscula torre se construyó enrasada con el perfil norte que tendría la nueva iglesia, pero ajena a su desarrollo mate-

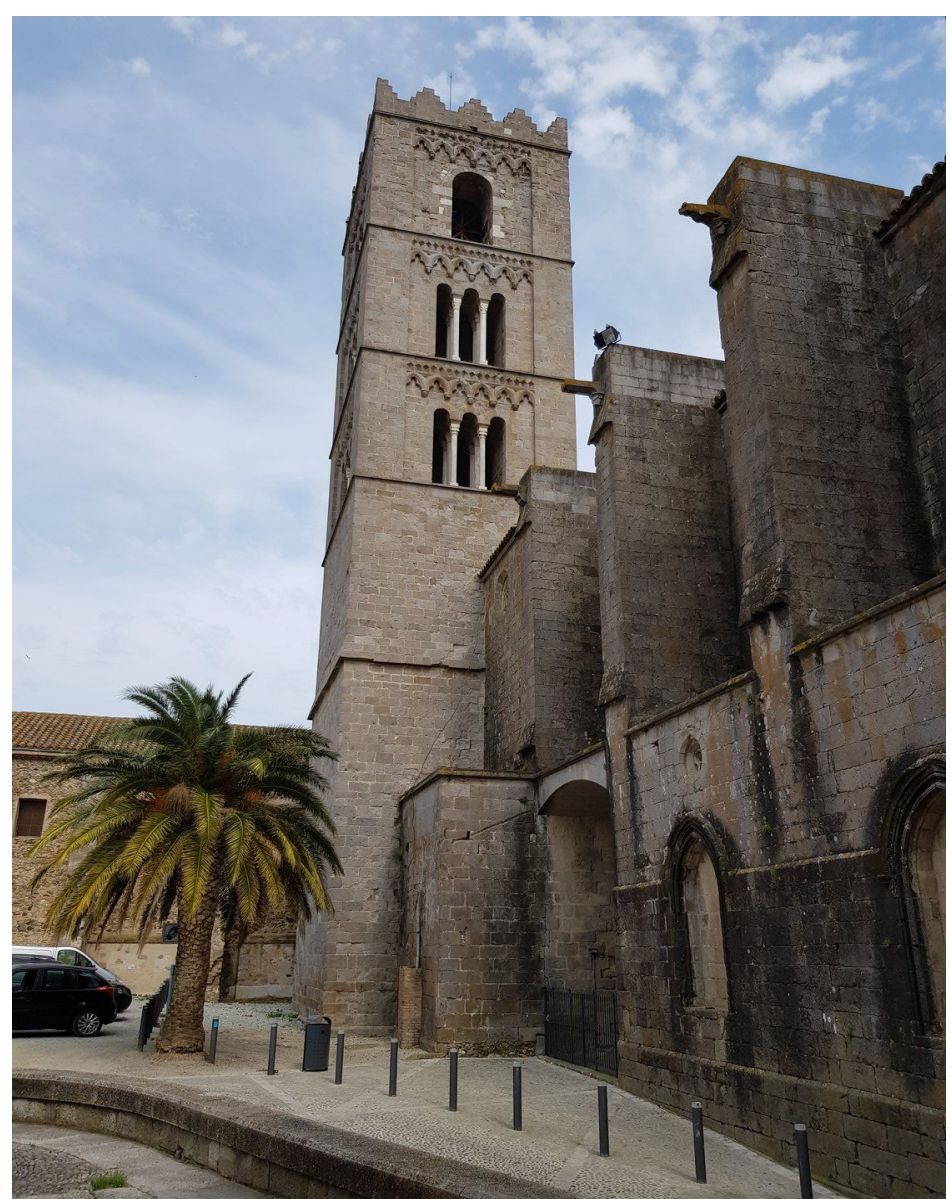

IMAGEN 7 - Torre campanario de Santa Maria de Castelló d'Empúries, desde el atrio norte. Foto del autor.

rial (Tremoleda 2013: 48). Fue edificada como un prisma aislado, a tres vientos y una cara hacia un futuro espacio interior del templo con un vano abierto, que permitía ingresar en el ámbito de planta cuadrada destinado a capilla (Imagen 7 ). El baluarte se ejecutó de ese modo en el primer impulso constructivo, desde el nivel de circula- ción hasta la hilada vigesimotercera. En esa coordenada, justo una hilada por encima de la clave de la contigua capilla de Sant Jaume - situada aproximadamente a la misma altura que la clave de los tramos de las naves laterales en el primer proyecto, esto es, la cota de abovedamiento que habría tenido el cuarto tramo de la nave si no se hubiera sustituido el primer proyecto constructivo por el segundo-, la torre aún no contaba con ninguna solución para facilitar el acceso al futuro cuerpo de campanas. Carecía de una escalera propia y, por ende, era subsidiaria de la construcción de la caja de escalera de caracol, insólitamente segregada de la torre, en lugar de formar cuerpo con el campanario o ser adyacente a sus paramentos.

En cambio, desde su segundo cuerpo la torre quedó integrada con el muro de cierre del tercer tramo de la nave lateral, con el que traba en toda su extensión vertical (Imagen 8). Se puede advertir en ese punto cómo repercutió la mudanza constructiva del primer al segundo proyecto o, dicho de otro modo, cuál fue el nuevo criterio que se observó cuando se retomó la construcción del campanario. Para acotar los márgenes cronológicos de esta variación es provechoso invocar la noticia referida a la compra de columnas para ornar el tercer y cuarto piso, correspondientes al cuerpo de campanas: en 1311 Arnau Font vendió 20 columnas «ad opus cloquerii quod de novo inceptum est in dicta ecclesia» (Gironella 2017: 36). En ese año el campanario, que ya estaba construido en parte, era "comenzado de nuevo». Por tanto, poco antes de 1311 se había retomado la construcción, ahora ya por encima de las cubiertas de las naves laterales bajas, donde había quedado interrumpido el primer proyecto. Aunque no se precisa el lapso temporal transcurrido, es obvio que la responsabilidad de ese cambio debe ser atribuida a Pere Pedrer, contratado como maestro de obras en 1305. Y puesto que la construcción del segundo 
nivel de la torre es solidaria con el muro contiguo hacia levante y que la ejecución de ambos elementos fue requerida por la nueva formulación arquitectónica, la mutación del primer proyecto al segundo proyecto tuvo que producirse necesariamente con anterioridad a 1311; diría que en torno a 1305. En el muro sur de la torre, el que encara a las naves, se puede reconocer que estaba ya construida hasta la trigésima séptima hilada (primer y segundo nivel) cuando todas esas hiladas fueron quebradas por la inserción a posteriori de pilastras articuladas destinadas a soportar los perpiaños y los cruceros altos del cuarto tramo de la nave colateral del Evangelio. Tanto en la caja de la escalera como en la torre se manifiesta la imprevisión de insertar desde un inicio pilastras para apear arcos y delimitar

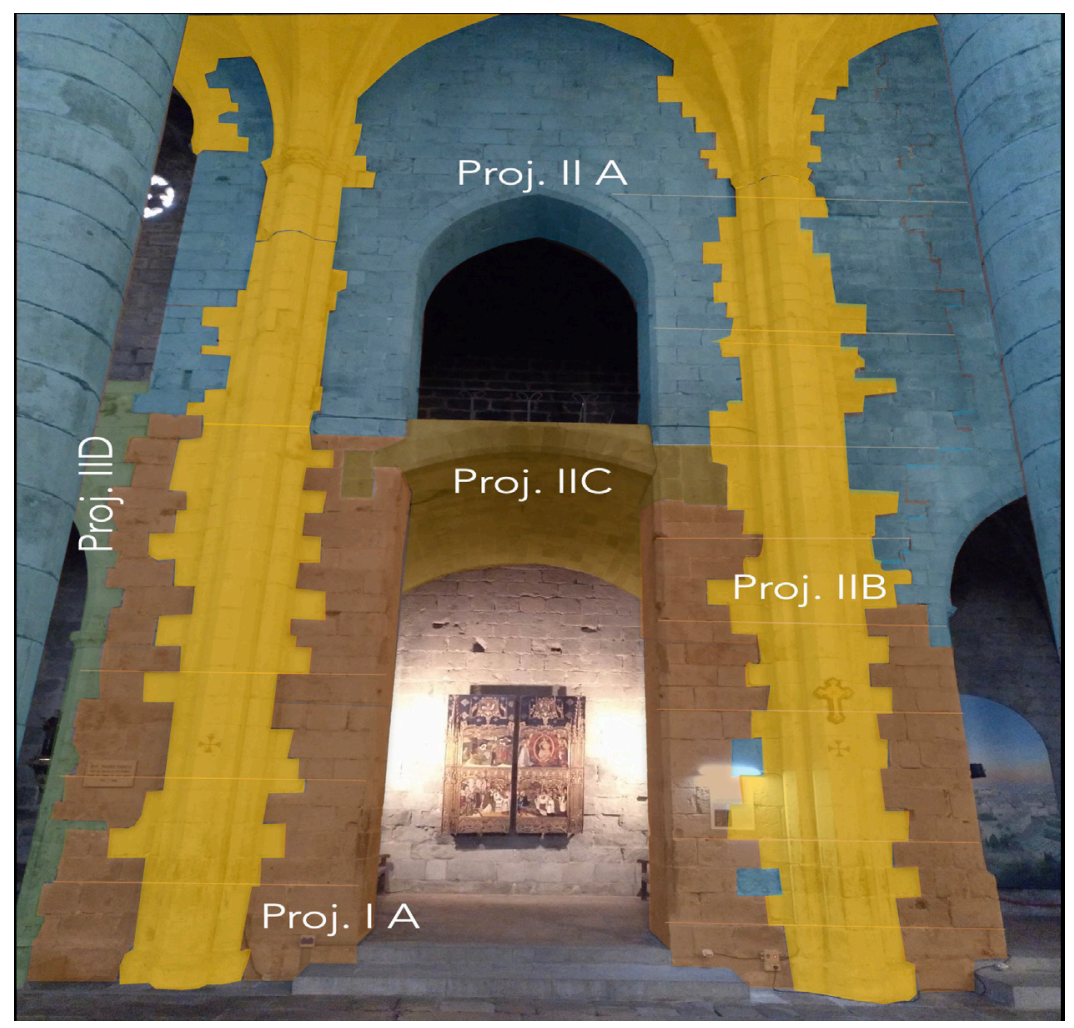

IMAGEN 8 - Fases constructivas de la torre campanario de Santa Maria de Castelló d'Empúries, desde la nave norte. (c) del autor.

la extensión de las crujías de la nave del Evangelio. Sin poder plantear una respuesta concluyente para esta negligencia, parece que la construcción de ambos cuerpos se llevó a cabo omitiendo el desarrollo longitudinal de la iglesia, que ya se estaba consumando con mayor celeridad (décadas de 1270-1290) en la nave de la Epístola, en particular hasta el arranque de su quinto tramo.

En suma, Pere Pedrer introdujo el nuevo planteamiento $c a$. 1305-1310, esto es, pocos años después de que se iniciara la construcción de la catedral de Barcelona y con anterioridad a que se pusiera la primera piedra de la catedral gótica de Girona. Ese cambio de proyecto precedió en un lustro al menos la consagración de la iglesia y del altar mayor de Santa Maria en 1315-1316. Con certeza en ese año los tres ábsides y los primeros tramos de las naves estaban construidos. No obstante, como he intentado argumentar, entiendo muy plausible que el abovedamiento de los ábsides se hubiera consumado antes de 1294.

De acuerdo con este orden cronológico, que viene fundamentado por una referencia documental y por la constatación material de que la

continuidad constructiva de la torre se efectuó al tiempo que se edificaba el muro de la nave lateral al que está adherida - en el nuevo contexto del segundo proyecto-, de ninguna manera se puede afirmar que la propuesta de Pere Pedrer fue una automática réplica de una fórmula ya generalizada entre los maestros de obra de la Cataluña del segundo cuarto del siglo XIv. Lo cierto es que en el horizonte de 1305-1315 las nuevas proposiciones estructurales y tectónicas se estaban ensayando y ejecutando solo en algunas lonjas, como la sede de Barcelona y en Cervera (Beseran 2003). Aún no constituía una tendencia extendida en todo el Principado, aunque así sucediese al cabo de poco. Considerando los hechos, tiempos y protagonistas en Castelló d'Empúries quizá quepa interpretar que la sustitución de proyectos tuvo algo - $\mathrm{o}$, más bien, mucho- que ver con el funcionamiento arriesgado de los arbotantes. La consecuencia inmediata del cambio de proyecto, atribuible a Pere Pedrer, fue la obtención de una espacialidad mas diáfana y homogeneizada (Lavedan 1935: 175).

La mudanza proyectual comportó la cons- 
trucción de paredones verticales por encima del perpiaño que separa el segundo y el tercer tramo en ambas naves laterales. El muro de la nave del Evangelio está perfectamente aparejado, con sillares de finos perfiles e hiladas impecables que prosiguen desde el espolón de la caja de la escalera. En cambio, el lienzo homólogo de la nave sur se facturó de manera precipitada y desmañada. En el costado exterior de ambos muros, específicamente en el extremo inmediato al botarel, se dejó preparado el arranque - con columna o con dovelas- de un arco crucero. Dado que ni en el botarel frontero - el que corresponde al límite del primer y del segundo tramo- ni en el muro de cierre de la nave mayor existe ninguna evidencia de arranques de nervios, habrá que descartar que se pensase abovedar esos espacios exteriores, y menos que se llegara a efectuar la cubrición de unas presuntas capillas, que jamás existieron. Antes bien, los brotes de las nervaduras constituyen un recurso preventivo para poder lanzar esos cruceros en el indeseable caso de que se necesitase contrarrestar desplazamientos de los muros de cierre o del tercer botarel, lo que nunca sucedió. Además, las pinturas murales de la cara interna del paredón de la nave de la Epístola, que han sido advertidas y son objeto de análisis por parte de Màrius Vendrell y Pilar Giráldez del laboratorio Patrimoni 2.0, son fechables en las décadas centrales del siglo XIV. Las pinturas manifiestan que ese cierre no se perforó, aunque en él aparezcan dos hornacinas.

Un último aspecto en este apartado. Cuando la torre ya estaba construida hasta la altura de las bóvedas de la nave contigua, se subdividió la altura de la capilla para generar un forjado en alto, al que solo se puede acceder por una perforación grosera que se practicó en el muro oriental de la torre. De este modo quedaron superpuestos dos oratorios privados. El altar y beneficio de Sant Nicolau pasó al piso alto, mientras Pere Bardoner fundaba en el año 1325 el altar y beneficio de Sant Pau (Marqués 1977: 59; Cobos, Tremoleda \& Vega 2010: 38; Tremoleda 2013: 76); no obstante, la ausencia de heráldica e inscripciones mantiene la duda sobre Bardoner como verdadero fundador de la capilla en sí misma (Cobos, Tremoleda \& Vega 2010: 38). La ausencia tanto en la capilla baja como alta de la heráldica del conde Hug IV
(1200-1230), fundador de la capilla de Sant Nicolau en 1219 aún dentro de la torre románica, se explica porque esas transformaciones fueron llevadas a cabo un siglo después de su muerte y omitiendo su memoria; precisamente en 1325 comenzó la trayectoria histórica de la segunda dinastía condal, de mano del conde Pere d'Aragó i Anjou (1325-1341).

\section{$\rightarrow$ 8. La transformación cultual del espacio eclesiástico de Santa Maria}

Antes del año 1297 Guillem Esquerrer (o Escarrer) fundó la primera capilla privada en la iglesia parroquial de Santa Maria, dedicada a Sant Pere y a Sant Grau (Cobos, Tremoleda \& Vega 2010: 42; Tremoleda 2013: 82; Ribas 2001a). Este mismo personaje fue el promotor del beneficio de la capilla de Sant Joan Baptista - el absidiolo septentrional-en 1303 (Marqués 1977: 71; Freixas 2003: 52; Cobos, Tremoleda \& Vega 2010: 39).

La capilla de Sant Pere fue compuesta entre el segundo y el tercer contrafuerte de la nave lateral sur. Para ello se derribó el muro que mediaba entre ambos estribos, se construyó un nuevo lienzo enrasando con los ápices de los contrafuertes, se lanzó una bóveda de crucería que apeaba en ménsulas y se sobrealzó el pavimento de la capilla respecto a la cota de circulación de la contigua nave lateral. Esta operación fue reproducida en los tramos sucesivos, dando lugar respectivamente a las capillas de Sant Mateu y Sant Antoni, fechable en 1341 según Tremoleda (2013: 82). La lectura de paramentos permite advertir que los cinco primeros contrafuertes del costado sur de la iglesia estaban construidos cuando se tomó la decisión de convertir los espacios exteriores que mediaban entre ellos en capillas abiertas al espacio interior y destinadas a cultos particulares (Imagen 9). Esa transformación sobrevenida e imprevista en el primer proyecto constructivo pasó a ser parte del programa espacial y celebrativo de Santa Maria cuando la obra llegó al quinto tramo de la nave de la Epístola - al que corresponde y se abre la capilla de Sant Bernat, con beneficio fundado ya en 1390 (Tremoleda 2013: 82) $-\mathrm{y}$ al séptimo tramo de la misma nave meridional al que se abre la capilla de Sant Andreu, pro- 


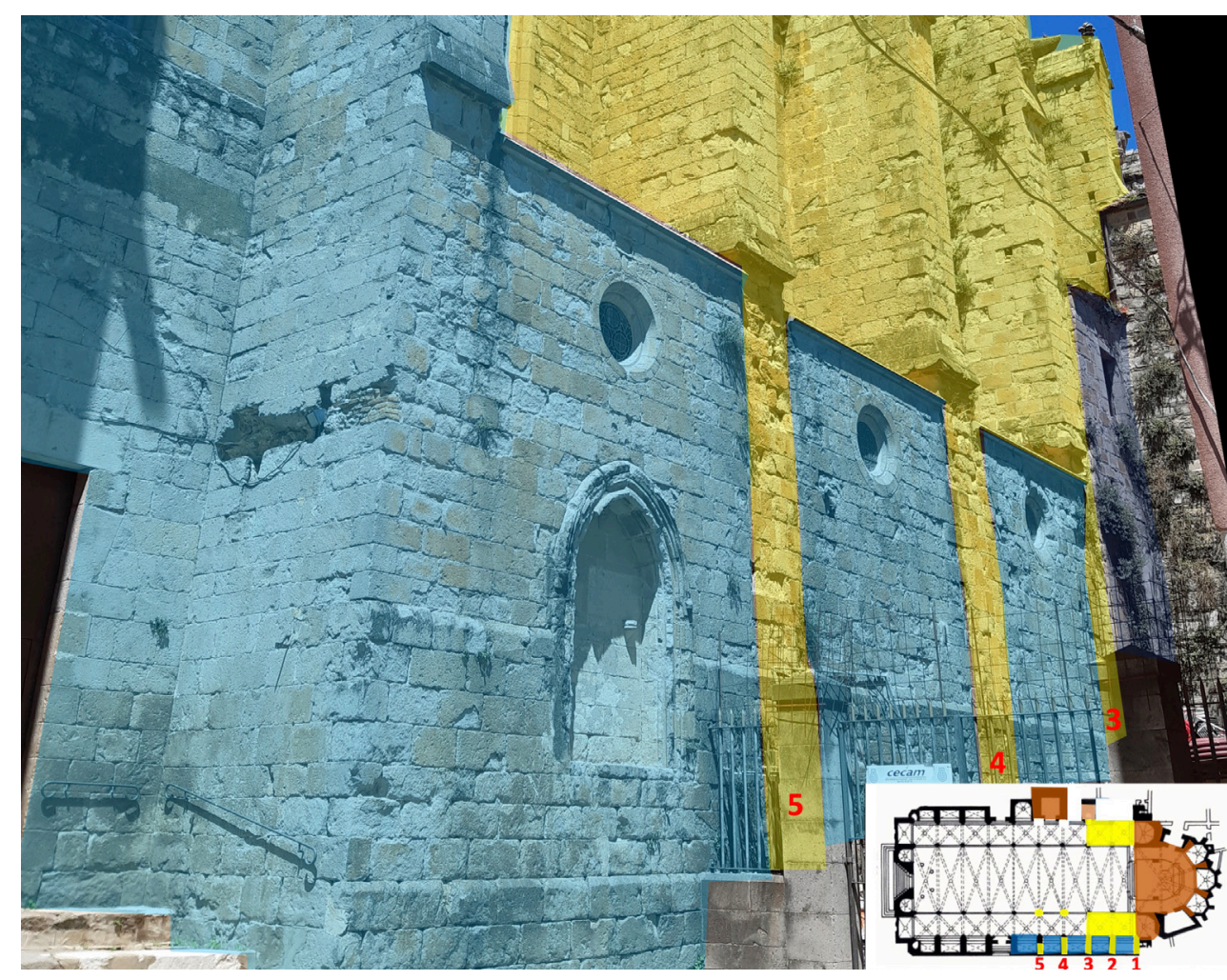

IMAGEN 9 - Muro de mediodía de Santa Maria de Castelló d'Empúries, con los contrafuertes enrasados y planta. (c) del autor.

movida por Berenguer Ballester en 1336 (Cobos, Tremoleda \& Vega 2010: 42).

En el lado norte, las transformaciones constructivas generadas para dar lugar a nuevas capillas se fijaron en los intervalos fronteros a los tres primeros tramos de la nave del Evangelio. El tramo más oriental estuvo murado desde el absidiolo de Sant Joan Baptista hasta el segundo contrafuerte. La transformación del espacio se operó con el mismo protocolo que en el caso de la capilla de Sant Pere, aunque no sabemos con certeza en qué momento y a cargo de qué promotor (Tremoleda 2013: 78). En el siglo xviII esa innominada capilla (Marqués 1977: 61; Cobos, Tremoleda \& Vega 2010: 39) se convirtió en el preámbulo de acceso a la capilla del Santíssim Sagrament (ca. 1740).

El sector correspondiente al segundo tramo de la nave, extendido entre el segundo contrafuerte y la caja de escalera helicoidal, se convirtió en la capilla de la Magdalena (Marqués 1977: 61; del Carmen según Ribas 2001a: 96). El examen de los paramentos no permite concluir que existiera un cierre que fuera desmontado para generar el espacio cultual privado.

El tercer sector, el que mediaba entre la caja de escalera y la torre nunca se tabicó mientras estuvo vigente el proyecto edilicio concebido por Reinald de Chartres. Cuando se formuló la segunda propuesta edificatoria para la iglesia de Santa Maria se construyó un muro en $\mathrm{L}$ desde la arista noroeste de la caja hasta un punto intermedio del paramento oriental de la torre. De esta suerte se cerró el espacio, que pudo ser empleado como capilla familiar $\mathrm{y}$, a posteriori, como panteón advocado a Sant Jaume. Conforme a la heráldica de la clave de bóveda, Cobos, Tremoleda \& Vega (2010: 38) plantean que la capilla fue fundada por Pere Bou hacia 1330, y que su hermano Ramon Bou fue el promotor de la capilla radial de Sant Esteve (Cobos, Tremoleda \& Vega 2010: 40; Tremoleda 2013: 76).

En las tres capillas del mismo flanco norte de la iglesia, el arco perpiaño de ingreso a cada una de ellas presenta una traza y unos soportes que son idénticos a los empleados ya en la capilla de Sant Pere, antes de 1297. Se advierte en la fábrica de Santa Maria la voluntad de mantener fórmulas decorativas para partes análogas de la iglesia, al margen del tiempo transcurrido entre la ejecución de un extremo y otro, sean estos capillas o pilares de segregación de naves.

En suma, si la reinterpretación del espacio cultual tuvo lugar antes de 1297, el planteamiento de las capillas perimetrales formulado con el avance de la fábrica $-\mathrm{y}$ ya no instaladas de manera sobrevenida-, se concibió antes de 1336 . 


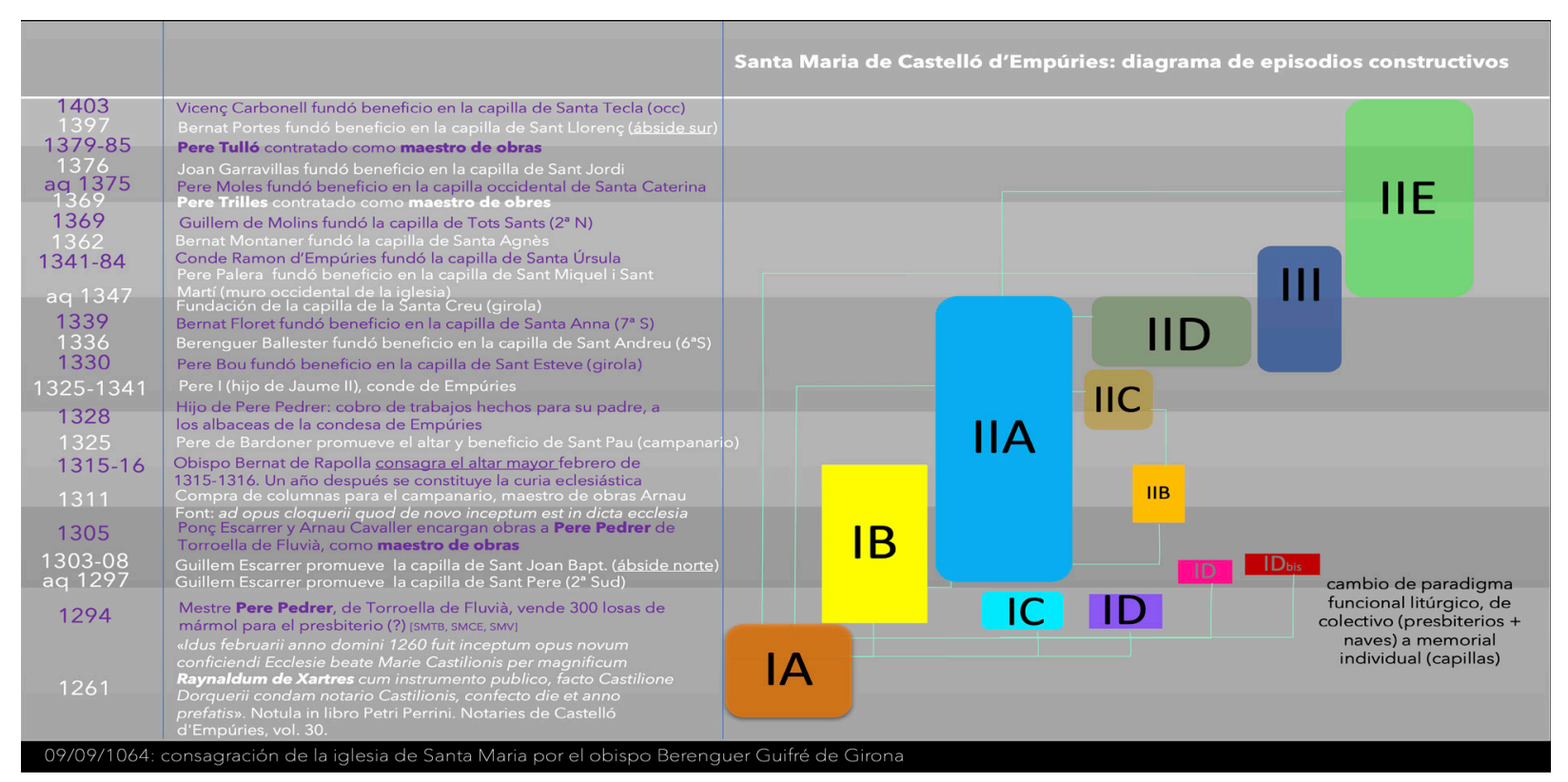

IMAGEN 10 · Santa Maria de Castelló d'Empúries. Diagrama de episodios constructivos. (c) del autor.

\section{$\rightarrow$ 9. Conclusión}

El planteamiento y mutaciones de Santa Maria de Castelló d’Empúries ofrece unos perfiles arquitectónico y social muy relevantes en el paisaje catalán del último tercio del siglo xiII e inicios de la centuria siguiente. Esta fábrica fue concebida como una iglesia parroquial de tres ábsides, de descollantes y ostentosas dimensiones el central, pero sin el ánimo de dotarse de una compleja articulación devocional y ritual, a la manera de las iglesias monásticas (benedictinas o cistercienses) o catedralicias. Ese programa funcional de vocación y uso colectivo, limitado a la existencia de tres altares y otras tantas naves, se vio alterado y enriquecido por la adición de capillas dotadas por individuos conspicuos en la comunidad local, nobles y burgueses, o por gremios profesionales. Esas capillas se prodigaron en los contornos longitudinales y poligonales del templo, perforando sistemáticamente los muros inicialmente construidos y desplazando los cierres del espacio eclesiástico hasta un segundo y más centrífugo perímetro. Esta vía de alteración del espacio cultual abrió una fuente de financiación complementaria para el progreso de la obra y una oportunidad de exhibición y rememoración social para sus propietarios. La universidad, la casa condal y la curia eclesiástica coral compartieron -y compitieron por- el uso y provecho espiritual y estamental de la iglesia y sus ámbitos delimitados (Imagen 10).

\section{$\rightarrow$ Referencias bibliográficas}

BADIA I Homs, Joan, 1978: L'arquitectura medieval de l'Empordà. II-A Alt Empordà (Agullana-Peralada), Girona, Diputació de Girona.

Barrachina NAVArRo, Jaime, 1998-99: «Las portadas de la iglesia de Sant Pere de Rodes», Locus Amoenus, $4,7-35$.

BARRAQUer y Roviralta, Cayetano, 1906: Las casas de religiosos en Cataluña durante el primer tercio del siglo XIX, Barcelona, Imp. de Francisco J. Altés y Alabart, 2 vols.

Beseran i Ramon, Pere, 2003: «Santa Maria de Cervera», L'art gòtic a Catalunya. Arquitectura II: catedrals, monestirs $i$ altres edificis religiosos (2), coord. Josep Bracons, Pere Freixas, Barcelona, Enciclopèdia Catalana, 39-50.

Bony, Jean, 1983: French Gothic Architecture of the 12th \& 13 th Centuries, Berkeley-Los Angeles-London, University of California Press.

Bracons, Josep, 2002a: «La seqüència de l'arquitectura gòtica catalana amb relació a l'europea», L'art gòtic a Catalunya. Arquitectura I: catedrals, monestirs i altres edificis religiosos (1), coord. Josep Bracons, Pere Freixas, Barcelona, Enciclopèdia Catalana, 18-29.

BRACONS, Josep, 2002b: «Experimentació i innovació en l'arquitectura del segle XIII", L'art gòtic a Catalunya. Arquitectura I: catedrals, monestirs i altres edificis religiosos (1), coord. Josep Bracons, Pere Freixas, Barcelona, Enciclopèdia Catalana, 52-57.

Вото, Gerardo, 2015: «Metaphora, mirar la materia para ver lo etéreo. La puerta claustral de la catedral de Tarragona», Románico, 20, 24-33.

Boto, Gerardo; Serrano, Marta, 2018: «Acción cons- 
tructiva y memoria monumental de los arzobispos de Tarragona en los escenarios de la catedral (siglo XIv)», Obispos y Catedrales. Arte en la Castilla bajomedieval, ed. María Victoria Herráez et al., Berna, Peter Lang, 563-605.

CArrero, Eduardo, 2017: «Santa María de Castelló d'Empúries: el doble proyecto gótico y la definición de su espacio», El Juicio Final. Sonido. Imagen. Liturgia. Escena, ed. Maricarmen Gómez Muntané, Madrid, Editorial Alpuerto, 337-349.

Carsalade, Monique, 1992: «L'église Sainte-Marie de Castello d'Empuries [sic] et son décor sculpté (Catalogne)», Archéologie du Midi médiéval, 10, 157-166.

Cobos Fajardo, Antoni; Tremoleda Trilla, Joaquim; Vega Ferrer, Salvador, 2010: L'epigrafia medieval dels comtats gironins. II. El comtat d'Empúries, Figueres, Brau.

Conejo da Pena, Antoni (ed.), 2016: L'infant Pere d'Aragó i d'Anjou: «molt graciós e savi senyor», Vandellós i l'Hospitalet de l'Infant-Valls, Ajuntament de Vandellòs i l'Hospitalet de l'Infant-Cossetània.

Constans, Lluís G., 1987: Diplomatari de Banyoles, Banyoles, Centre d'Estudis Comarcals de Banyoles, vol. 2.

Cosmen, María Concepción, 2016: «Paisajes artísticos velados. La cabecera románica de la catedral de Sigüenza y la posible difusión del modelo», De arte: revista de historia del arte, 15, 7-32.

Du CANGE, Charles du Fresne, 1842: Glosssarium mediae et infimae latinitatis, París, Didot, vol. 2.

Du CANGE, Charles du Fresne et al., 1886: Glossarium mediae et infimae latinitatis, Niort, L. Favre, vol. 7. Edició en línia: <http://ducange.enc.sorbonne.fr/> [07/07/2021].

Durand, Paul, 1864: Chapelle de la Sainte-Vierge en l'église de Saint-Père à Chartres: explication de la nouvelle décoration, Chartres, Impr. de Garnier.

Frauer, Martina, 1999: «Die Dominikanerkirche Santa Catalina in Barcelona - Aspekte zur Entstehungsgeschichte», Gotische Architektur in Spanien. Akten des Kolloquiums der Carl Justi-Vereinigung und des Kunstgeschichtlichen Seminars der Universität Göttingen, ed. Christian Freigang, Madrid-Frankfurt, Vervuert-Iberoamericana (Ars Iberica, 4), 120-142.

Freigang, Christian, 1992: Imitare ecclesias nobiles. Die Kathedralen vom Narbonne, Toulouse und Rodez die nordfranzösische Rayonnantgotik mit Languedoc, Worms, Wernersche Verlagsgesellschaft.

Freigang, Christian, 1995a: «Les rois, les évêques et les cathédrales de Narbonne, de Toulouse et de Rodez», La Cathédrale: XII ${ }^{e}$-XIV viècle, Tolosa, Privat (Cahiers de Fanjeaux, 30), 145-183.

Freigang, Christian, 1995b: «La organización del taller en el sur de Francia en los siglos XIII y XIV: el ejemplo de Narbona en Talleres de Arquitectura en la Edad Media», Talleres de Arquitectura en la Edad
Media, dir. Roberto Cassanelli, Barcelona, Moleiro, 169-194.

FreigANG, Christian, 2002a: «L'arquitectura mendicant al Llenguadoc i la seva relació amb Catalunya», L'art gòtic a Catalunya. Arquitectura I: catedrals, monestirs $i$ altres edificis religiosos (1), coord. Josep Bracons, Pere Freixas, Barcelona, Enciclopèdia Catalana, $170-172$.

FreigANG, Christian, 2002 $b$ : «La catedral de Narbona com a referent directe de les Barcelona i Girona», L'art gòtic a Catalunya. Arquitectura I: catedrals, monestirs $i$ altres edificis religiosos (1), coord. Josep Bracons, Pere Freixas, Barcelona, Enciclopèdia Catalana, 270-273.

FreiXas I CAmps, Pere, 2002: «El convent de Sant Domènec de Girona», L'art gòtic a Catalunya. Arquitectura I: catedrals, monestirs i altres edificis religiosos (1), coord. Josep Bracons, Pere Freixas, Barcelona, Enciclopèdia Catalana, 219-223.

FreiXas I CAMPs, Pere, 2003: «Santa Maria de Castelló d'Empúries», L'art gòtic a Catalunya. Arquitectura II: catedrals, monestirs i altres edificis religiosos (2), coord. Josep Bracons, Pere Freixas, Barcelona, Enciclopèdia Catalana, 51-59.

FreiXas I CAmps, Pere, 2018: «Santa Maria dels Turers. Dubtes i certeses sobre el procés de construcció (1269-1330)», Arquitectura Gòtica a les terres de Girona. La construcció de l'església de Santa Maria dels Turers de Banyoles, ed. G. Boto, P. Freixas, J. Galofré, Banyoles, Centre d'Estudis Comarcals de Banyoles, 95-116.

FugUet i SANS, Joan, 1986-87: «Apreciacions sobre l'ús de les cobertes amb arcs diafragma a l'arquitectura medieval catalana», Acta Historica et Archaeologica Medievalia, 7-8, 437-451.

Fuguet i Sans, Joan, 1998: «Contribució a l'estudi dels orígens del gòtic meridional: influència de l'arquitectura popular en les construccions templeres i cistercenques catalanes», Miscelllània en homenatge a Joan Ainaud de Lasarte, Barcelona, Museu Nacional d'Art de Catalunya-Publicacions de l'Abadia de Montserrat, I, 225-236.

Fumanal, Miquel Àngel; Gironella, Josep Maria, 2018: «Els Pedrer de Torroella de Fluvià. Una nissaga de Mestres picapedrers empordanesos», Arquitectura Gòtica a les terres de Girona. La construcción de l'església de Santa Maria dels Turers de Banyoles, ed. G. Boto, P. Freixas, J. Galofré, Banyoles, Centre d'Estudis Comarcals de Banyoles, 69-94.

Genís I MAS, Daniel, 2002: «Les profecies de l'infant Pere d'Aragó (1305-1381): el comtat d'Empúries en l'inici del joaquimisme a Catalunya", Annals de l'Institut d'Estudis Empordanesos, 35, 119-140.

Gironella, Josep Maria, 2017: Castelló d'Empúries. Tot el que cal saber sobre la vila comtal empordanesa, Girona, Empordàbrava. 
GonzÁlez Moreno-NAVArro, José Luis, 2007: «El caso de los de arbotantes de la cabecera de la iglesia gótica de Castelló d'Empuries (la llamada "catedral del Ampurdán")", Actas del Quinto Congreso Nacional de Historia de la construcción, ed. Miguel Arenillas et al., Madrid, Instituto Juan de Herrera-SEdHC-CICCP-CEHOPU, 479-488.

Granero Villa, Xènia, 2018: «El proceso constructivo del monasterio de santa Maria de Vallbona de les Monges: consideraciossnes cronológicas y nuevas propuestas interpretativas», Codex Aquilarensis, 34, 291-316.

HÉliot, Pierre; Jouven, Georges, 1970-71: «L'église de Saint-Pierre de Chartres et l'architecture du Moyen Âge», Bulletin archéologique du Comité des travaux historiques et scientifiques, n. s. VI, 117-177.

Kimpel, Dieter; Suckale, Robert, 1990: L'Architecture gothique en France, 1130-1270, trad. Françoise Neu, París, Flammarion.

LAVEdAN, Pierre, 1935: L'Architecture gothique religieuse en Catalogne, Valence et Baléares, París, Henri Laurens.

Marqués Casanovas, Jaume, 1977: Santa María de Castelló d'Empúries, za edició, Castelló d'Empúries.

Molina Figueras, Joan, 2011: «La memòria de les pedres. Fundació i esplendor d'un convent dominicà a la Girona baixmedival», Universitat de Girona: Història, Arquitectura i Patrimoni, Girona, Universitat de Girona, 165-188.
Ortoll i MArtín, Ernest, 1996: «Algunas consideraciones sobre la iglesia de Santa Caterina de Barcelona», Locus Amoenus, 2, 47-63.

Pujol i Canelles, Miquel, 1989: «El retaule d'alabastre de Santa Maria de Castelló d'Empúries», Annals de l'Institut d'Estudis Empordanesos, 22, 67-96.

Ribas I Torres, Pasqual, 2001a: Òbits fossars i enterraments en el paviment de l'església parroquial de Santa Maria de Castelló d'Empúries, Castelló d'Empúries.

Ribas i Torres, Pasqual, 2001b: Atles de Castelló d'Empúries, Castelló d'Empúries, Ajuntament de Castelló d’Empúries.

SAIS I Bou, Iraida, 2017: Els artífexs de Santa Maria de Castelló d'Empúries: el llibre de procura 1411-1422/8, Universitat de Girona, Treball final de màster, dir. Joan Molina i Figueras, <http://hdl.handle. net/10256/14511>.

ThiéBAut, Jacques, 1972: «Saint-Père de Chartres [compte-rendu]», Bulletin Monumental, 130-131, 60-62.

TORrent I OrRI, Rafael, 1976: «El darrer comte d'Empúries sobirà, la reina empordanesa i la llotja de Castelló», Annals de l'Institut d'Estudis Empordanesos, 11, 217-251.

Torres BalbÁs, Leopoldo, 1952: Arquitectura gótica, Madrid, Plus-Ultra (Ars Hispaniae, 7).

Tremoleda i Trilla, Joaquim, 2013: La basílica de la llum de Castelló d'Empúries, Girona, Diputació de Girona. 